UCRL-ID-121264

\title{
LABAN \\ Containment Data Report
}

\author{
T. Stubbs \\ R. Heinle
}

May 1995

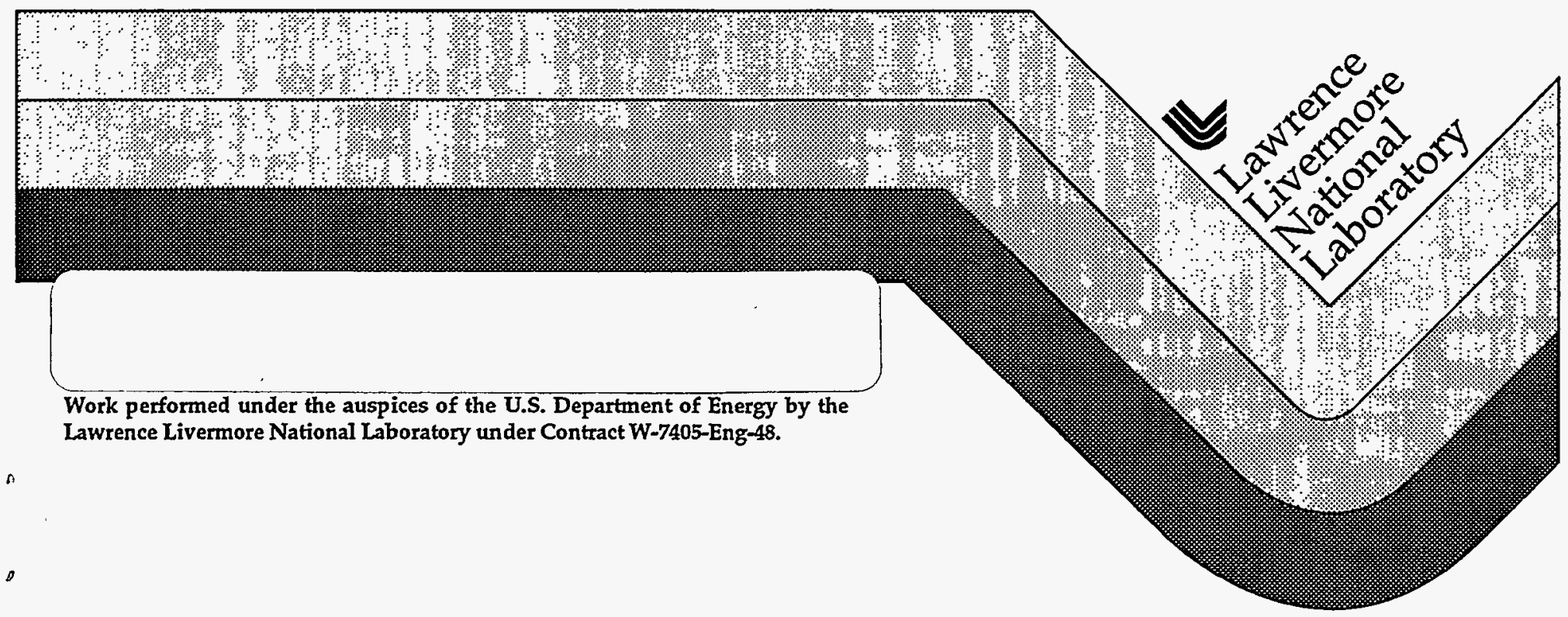




\section{DISCLAIMER}

This document was prepared as an account of work sponsored by an agency of the United States Government. Neither the United States Government nor the University of California nor any of their employees, makes any warranty, express or implied, or assumes any legal liability or responsibility for the accuracy, completeness, or usefulness of any information, apparatus, product, or process disclosed, or represents that its use would not infringe privately owned rights. Reference herein to any specific commercial products, process, or service by trade name, trademark, manufacturer, or otherwise, does not necessarily constitute or imply its endorsement, recommendation, or favoring by the United States Government or the University of California. The views and opinions of authors expressed herein do not necessarily state or reflect those of the United States Government or the University of California, and shall not be used for advertising or product endorsement purposes.

This report has been reproduced directly from the best available copy.

Available to DOE and DOE contractors from the Office of Scientific and Technical Information P.O. Box 62, Oak Ridge, TN 37831

Prices available from (615) 576-8401, FTS 626-8401

Available to the public from the National Technical Information Service U.S. Department of Commerce 5285 Port Royal Road Springfield, VA 22161 


\section{DISCLAIMER}

Portions of this document may be illegible in electronic image products. Images are produced from the best available original document. 
LABAN Instrumentation Summary

\begin{tabular}{|c|c|c|c|}
\hline Instrumentation & $\begin{array}{l}\text { Fielded on } \\
\text { this Event }\end{array}$ & $\begin{array}{c}\text { Data } \\
\text { Return }\end{array}$ & $\begin{array}{l}\text { Present in } \\
\text { this Report }\end{array}$ \\
\hline Plug Emplacement & yes & no & - \\
\hline Badiation & yes & yes & yes \\
\hline Pressure & & & \\
\hline Stemming & yes & yes & yes \\
\hline Challenge & no & - & - \\
\hline Cavity & no & - & - \\
\hline Atmospheric & no & $=$ & - \\
\hline Motion & & & \\
\hline Free Field & no & - & - \\
\hline Surface & yes & yes & yes \\
\hline Plug & yes & yes & yes \\
\hline Stemming & no & - & - \\
\hline Surface Casing & yes & yes & yes \\
\hline Emplacement Pipe(a) & yes & yes & yes \\
\hline Hydroyield (b) & yes & yes & no \\
\hline Collapse (c) & yes & yes & yes \\
\hline Stress & no & - & - \\
\hline Strain $^{(d)}$ & yes & yes & yes \\
\hline Other Measurements & no & - & - \\
\hline
\end{tabular}

(a) Relative displacement between pipe and stemming.

(b) CORTEX or SLIFER in emplacement hole.

(c) EXCOR or CLIPER in emplacement hole.

(d) Emplacement pipe.

\section{Event Personnel}

Containment Physics
B. Hudson
E. Woodward
J. Kalinowski
T. Stubbs
LLNL
LLNL
EG\&G/AVO
EG\&G/AVO

Instumentation

C. Cordill

R. Salazar

L. Davies

L. Farthing
LLNL

EG\&G/AVO

EG\&G/NVO

EG\&G/NVO 


\section{Contents}

1. Event Description

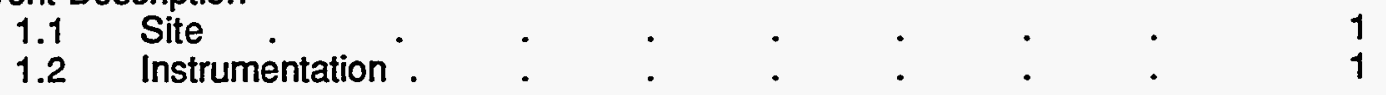

2. Emplacement

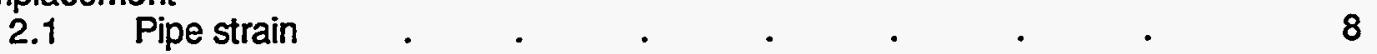

3. Stemming Performance

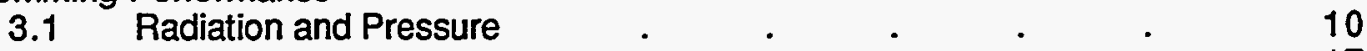

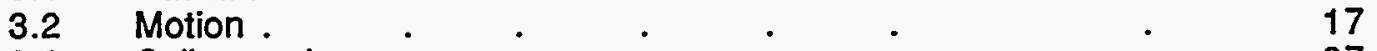

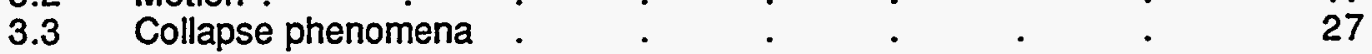

4. Phase Correction of an Over-damped Pendulum Velocity Gauge . $\quad$ - 35

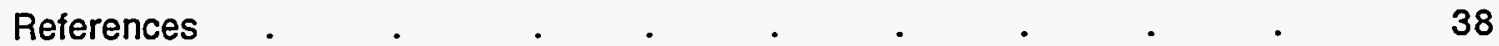




\section{Event Description}

\subsection{Site}

The LABAN event was detonated in hole U2ff of the Nevada Test Site as indicated in Figure 1.1. The device had a depth-of-burial of $326 \mathrm{~m}$ in the alluvium of Area 4, about $240 \mathrm{~m}$ above the standing water level (SWL), as shown in Figures 1.2 and 1.3.(1). Stemming of the $2.44 \mathrm{~m}$ diameter emplacement hole followed the plan shown in Fig. 1.4. A log of the stemming operations was maintained by Holmes \& Narver(2).

Detonation time was 06:33 PDT on August 3, 1983. About 75 minutes later the chimney began collapsing to the surface. A major collapse event occurred 5 minutes later with episodes continuing for the next 20 minutes.

No radiation arrivals were detected in the emplacement hole at depths less than $106 \mathrm{~m}$ and the LABAN containment was considered successful.

\subsection{Instrumentation}

Figure 1.5 is a schematic layout of the instrumentation designed to monitor the emplacement procedures and stemming performance of the LABAN event.

The two rigid stemming plugs were composed of two-part-epoxy (TPE), topped with a semi-liquid layer of coal tar and aggregate (CT/A) to act as a gas seal. The TPE plugs were about $5 \mathrm{~m}$ thick while the CT/A layers were about $1.5 \mathrm{~m}$ thick. An additional $3.4 \mathrm{~m}$ thick layer of CT/A was emplaced in the loose stemming about $45 \mathrm{~m}$ above the working point to act as a gas seal.

The coarse stemming of the emplacement hole was monitored for pressure and radiation at six locatons below the two rigid plugs, as shown in figure 1.5 . 
Vertical motion was monitored in the two rigid plugs, on the surface casing, and at $0.61 \mathrm{~m}$ depth in the ground surface, $15.24 \mathrm{~m}$ from SGZ (Surface-Ground-Zero). Relative displacement between the surface casing and the top plug, the surface casing and the stemming above the top plug, and the emplacement pipe and the stemming above the top plug was monitored by a set of three "fishing reel" displacement transducers.

Data from each of the above transducers were transmitted to the recording trailer by an analog system and recorded on magnetic tape.

Two CLIPER/CORRTEX sensors were emplaced, as indicated in figure 1.5, to measure the hydrodynamic yield of the device and to monitor cavity collapse and chimney formation. Results of the yield measurements are reported elsewhere(3).

A history of the fielding operations of the instrumentation, including the emplacement pipe strain measurements, is outlined in reference 4. Details of the instrumentation are given in reference 5. 


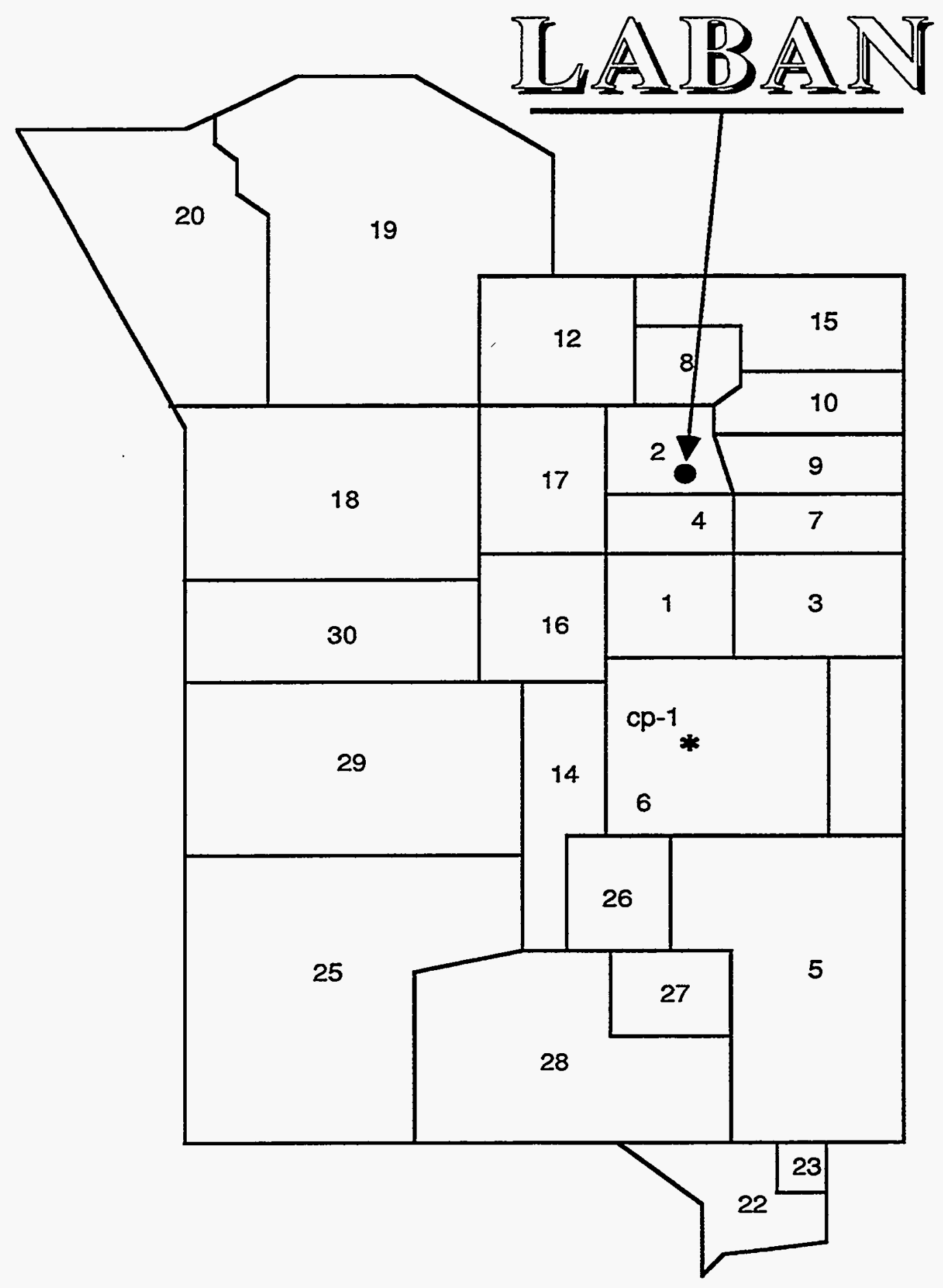

Figure 1.1 Map of the Nevada Test Site indicating the location of hole U2ff. 


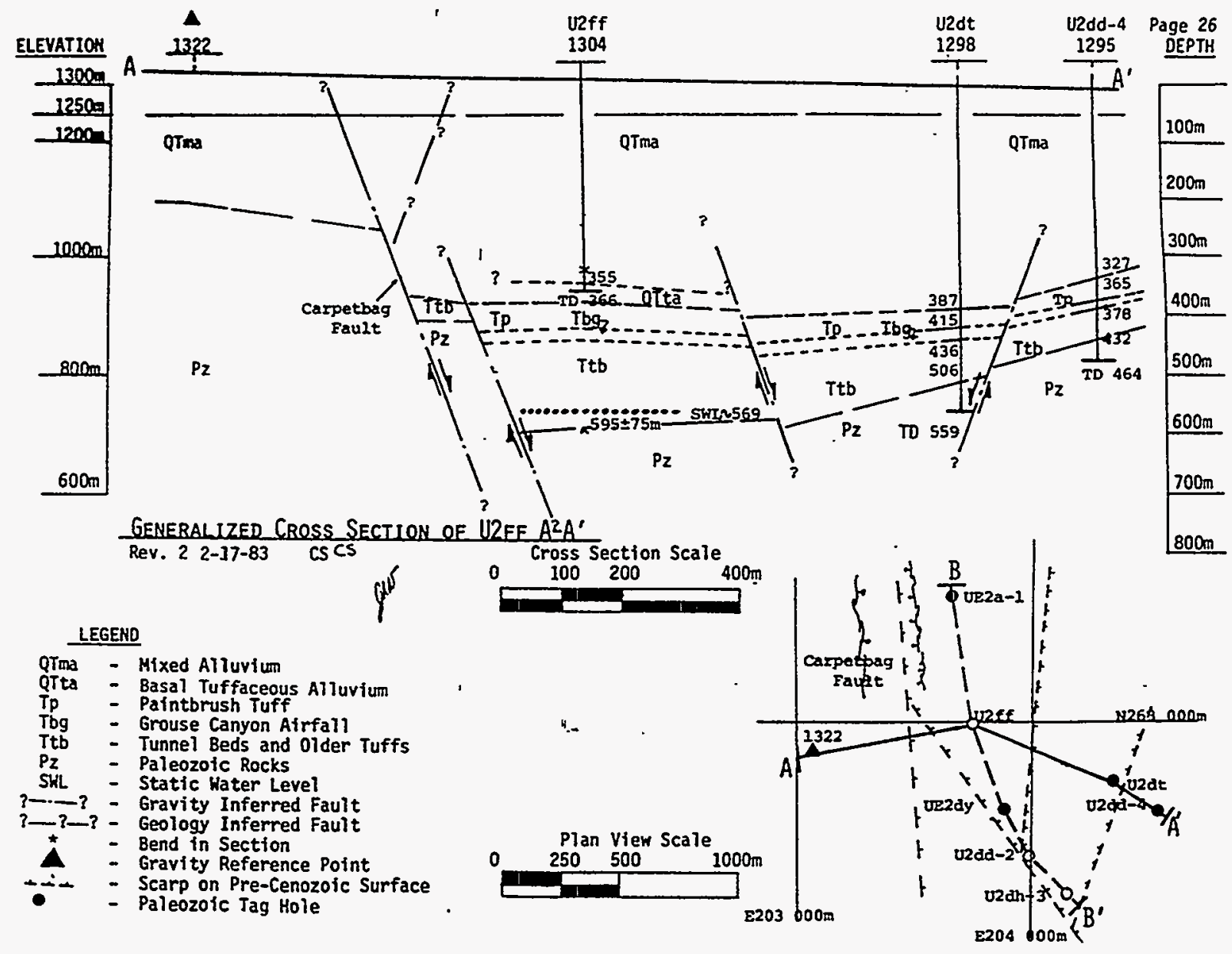

Figure 1.2 East-West geologic cross sections through hole U2ff. 


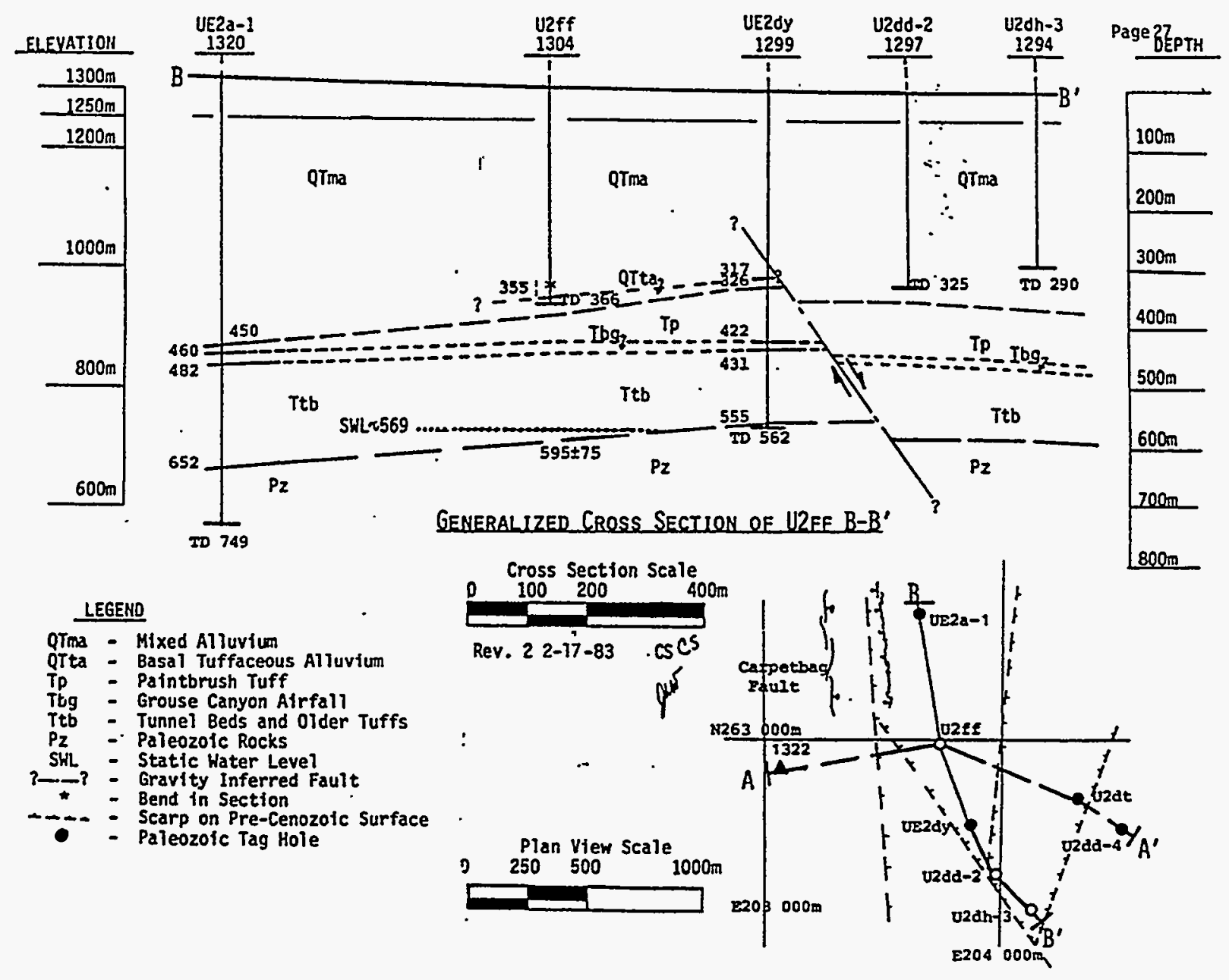

Figure 1.3 North-South geologic cross sections through hole U2ff. 


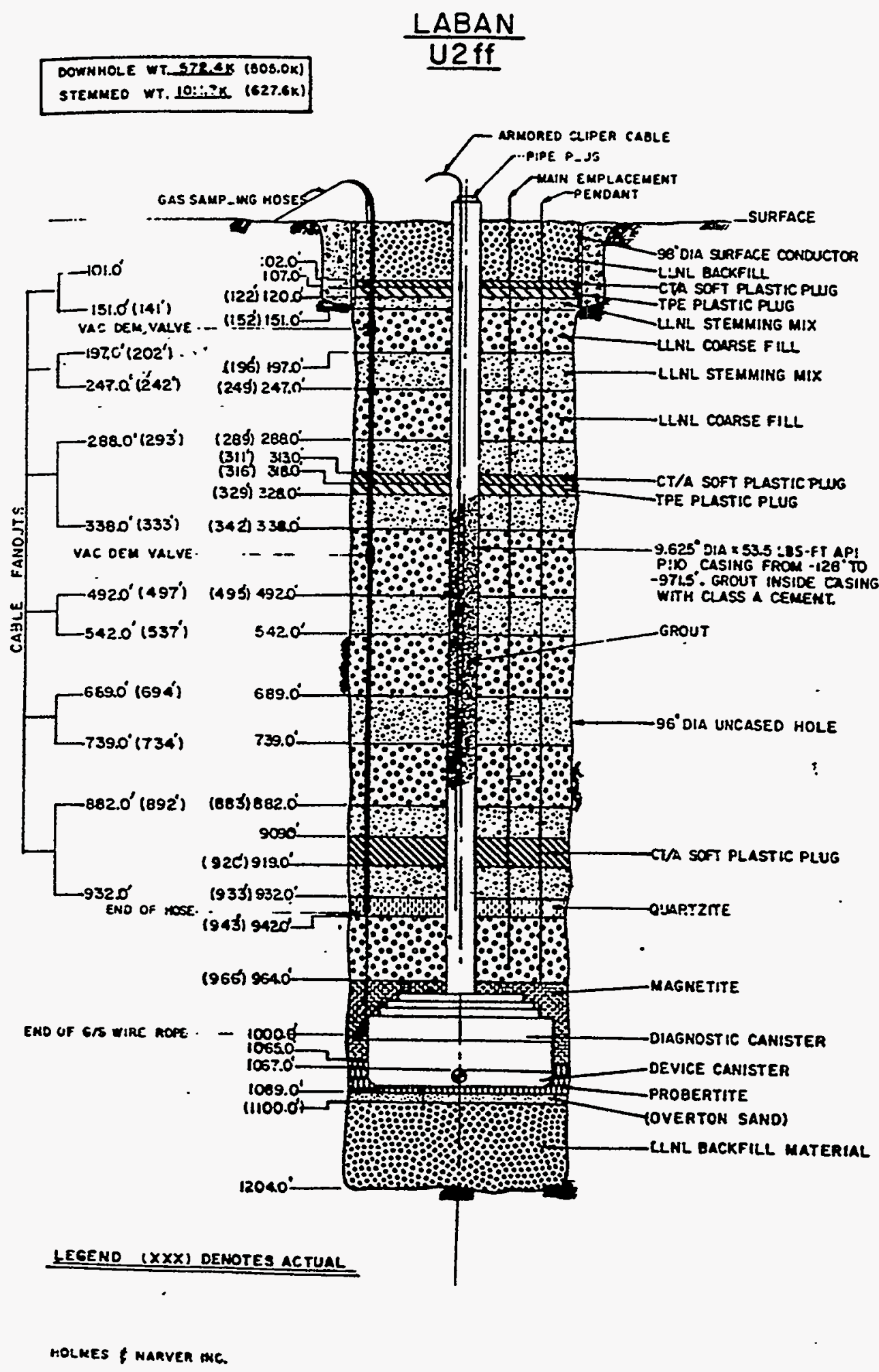

Figure 1.4 As-built stemming plan for the event LABAN in Hole U2ff. 


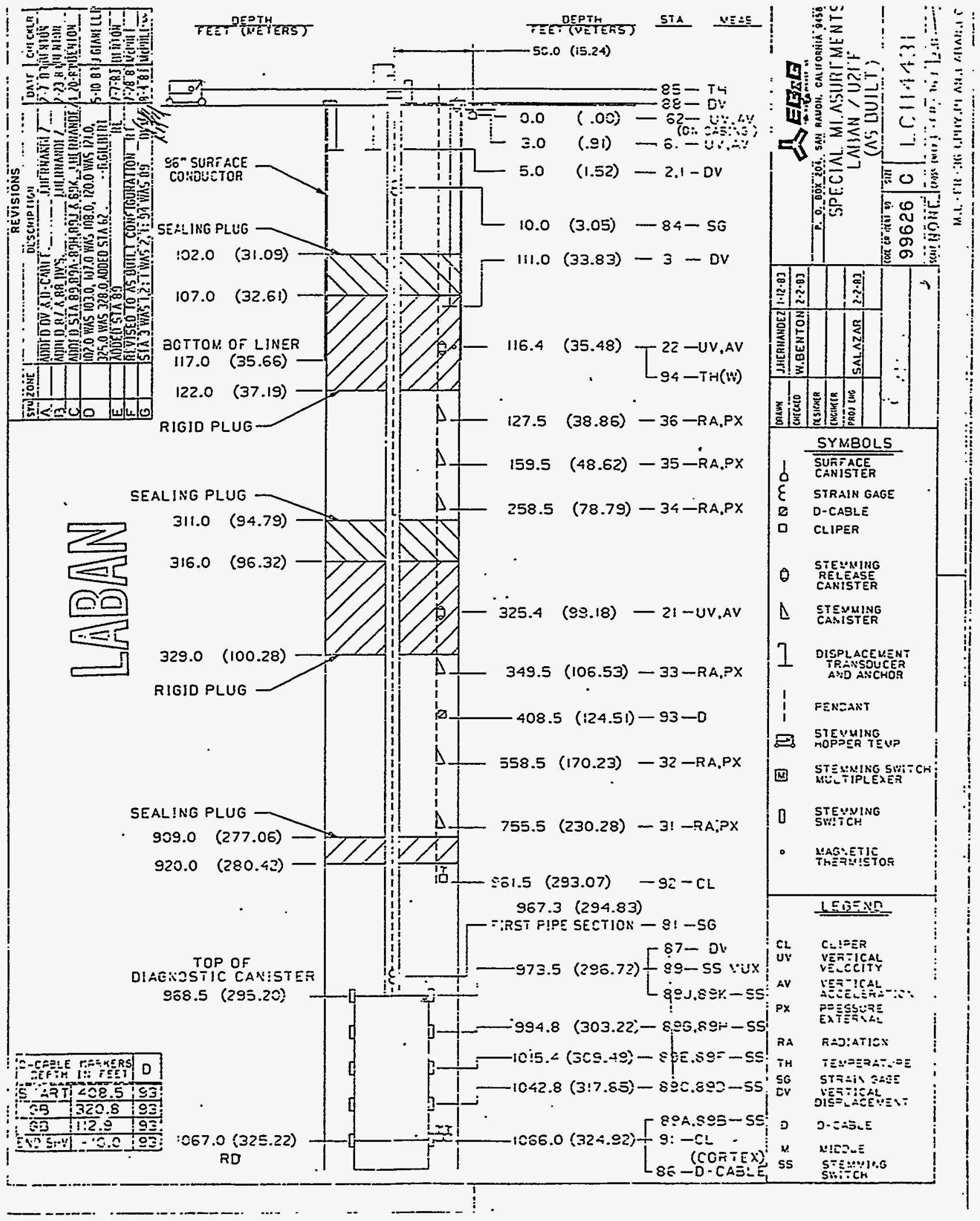

Figure 1.5 As-built containment instrumentation plan for the LABAN event. 


\section{Emplacement}

\subsection{Pine strain}

Figure 2.1 is the strain history measured on the emplacement pipe during stemming of the LABAN experiment. The emplacement pipe was instrumented with a strain gage station on the final pipe section just below the load collar (Station 84) and on the pipe just above the device canister. The data in figure 2.1 were taken from reference 2 wherein the information was recorded from time-to-time by hand. 

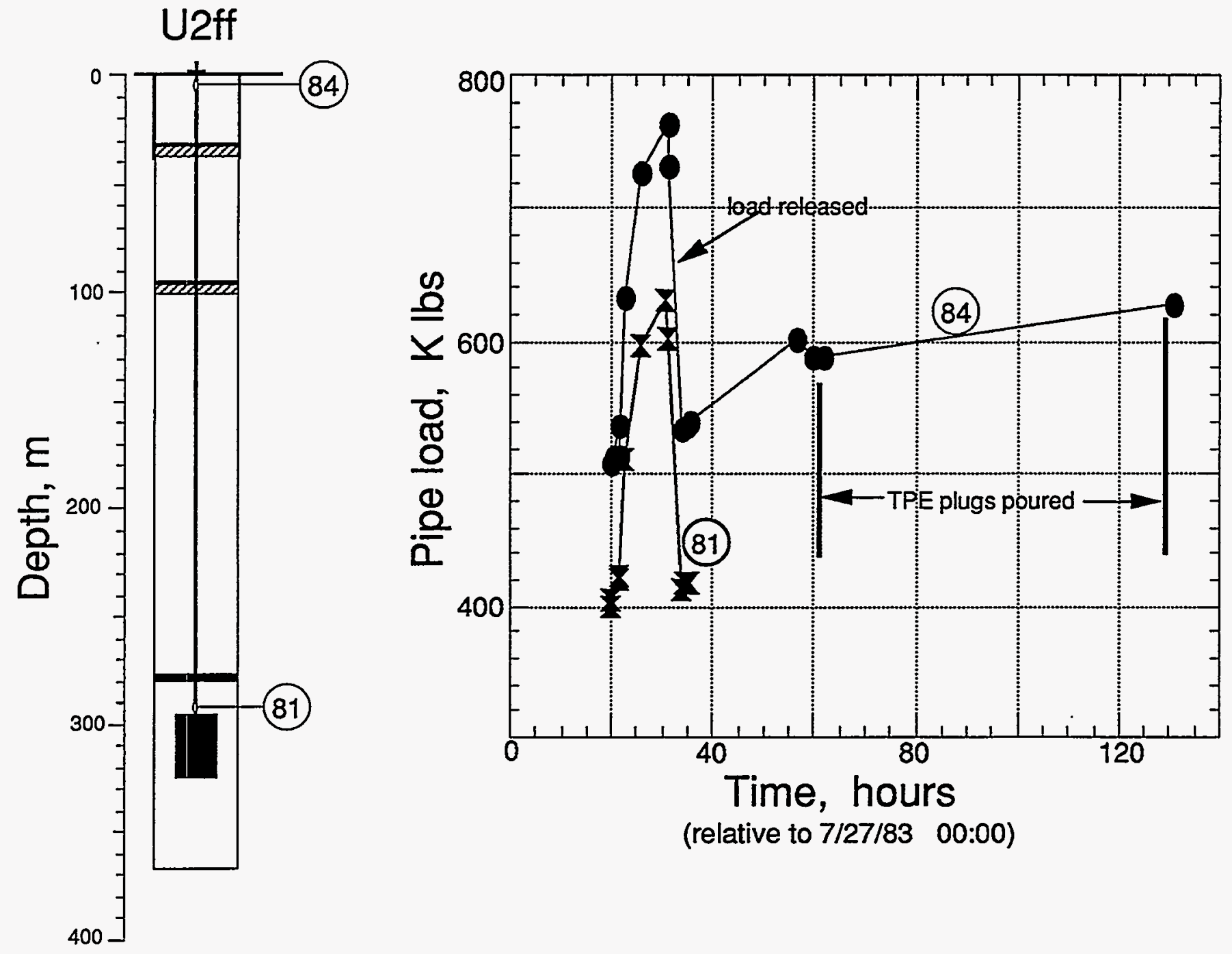

Figure 2.1 Strain measurements during the stemming at stations 84 (near the top of the pipe) and at station 81 (just above the device canister). Symbols denote the times at which the data were taken. 


\section{Stemming Performance}

\subsection{Radiation and Pressure}

As seen in figure 1.5, the coarse stemming between the two rigid TPE plugs and the deep CT/A gas seal was monitored by a set of six pressure and radiation stations. The signals were transmitted to the recording trailer in analog form and recorded on magnetic tape for later processing.

Pressure and radiation histories from a few seconds before detonation until loss of signal at cavity collapse (about 75 minutes later) are shown in figures 3.1-3.6. The deepest station in the coarse stemming (figure 3.1) shows a jump in pressure with no radiation. This pressure reaches a peak about 5 psi above ambient at around $150 \mathrm{~s}$. Station 32 (figure 3.2), in the stemming $60 \mathrm{~m}$ above station 31 , indicates the presence of radiation with a slight early jump in pressure (about $0.7 \mathrm{psi}$ ). Station 33 (figure 3.3), below the bottom TPE plug suggests the possibility of a radiation arrival with no pressure change. Neither pressure nor radiation change are observed above the bottom TPE plug.

Pressure measured at station 35 (figure 3.5) shows a drop characteristic of stemming fall at $4527 \mathrm{~s}$, the time of collapse initiation. Both the pressure and radiation signals continue for about another 2.5 minutes when they are lost, presumably due to cable breakage. These are the only pressure-radiation signals that lasted beyond the beginning of collapse.

These data are consistent with satisfactory containment. 

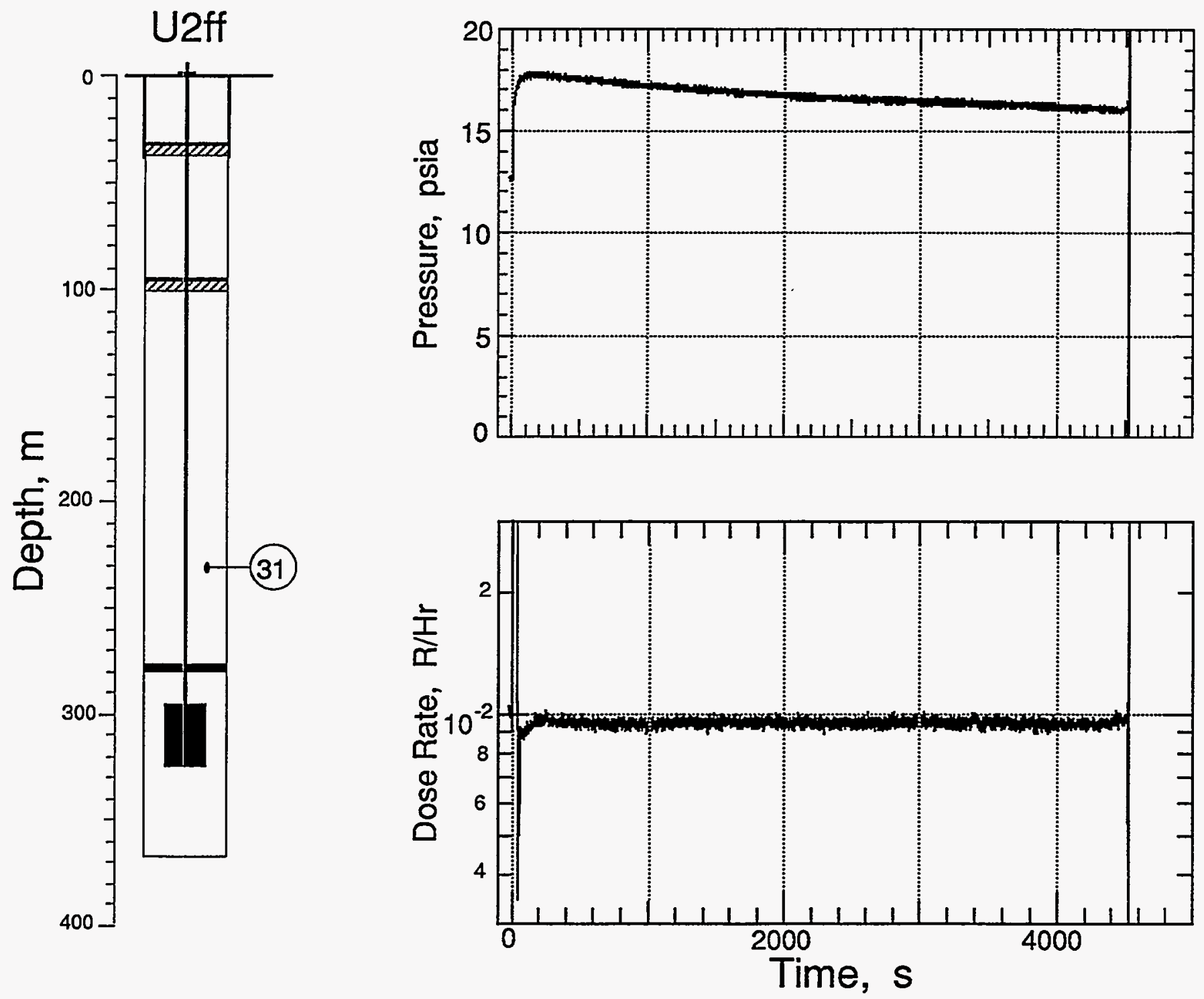

Figure 3.1 Pressure and radiation measured in the coarse stemming at a depth of $230 \mathrm{~m}$ (station 31). 

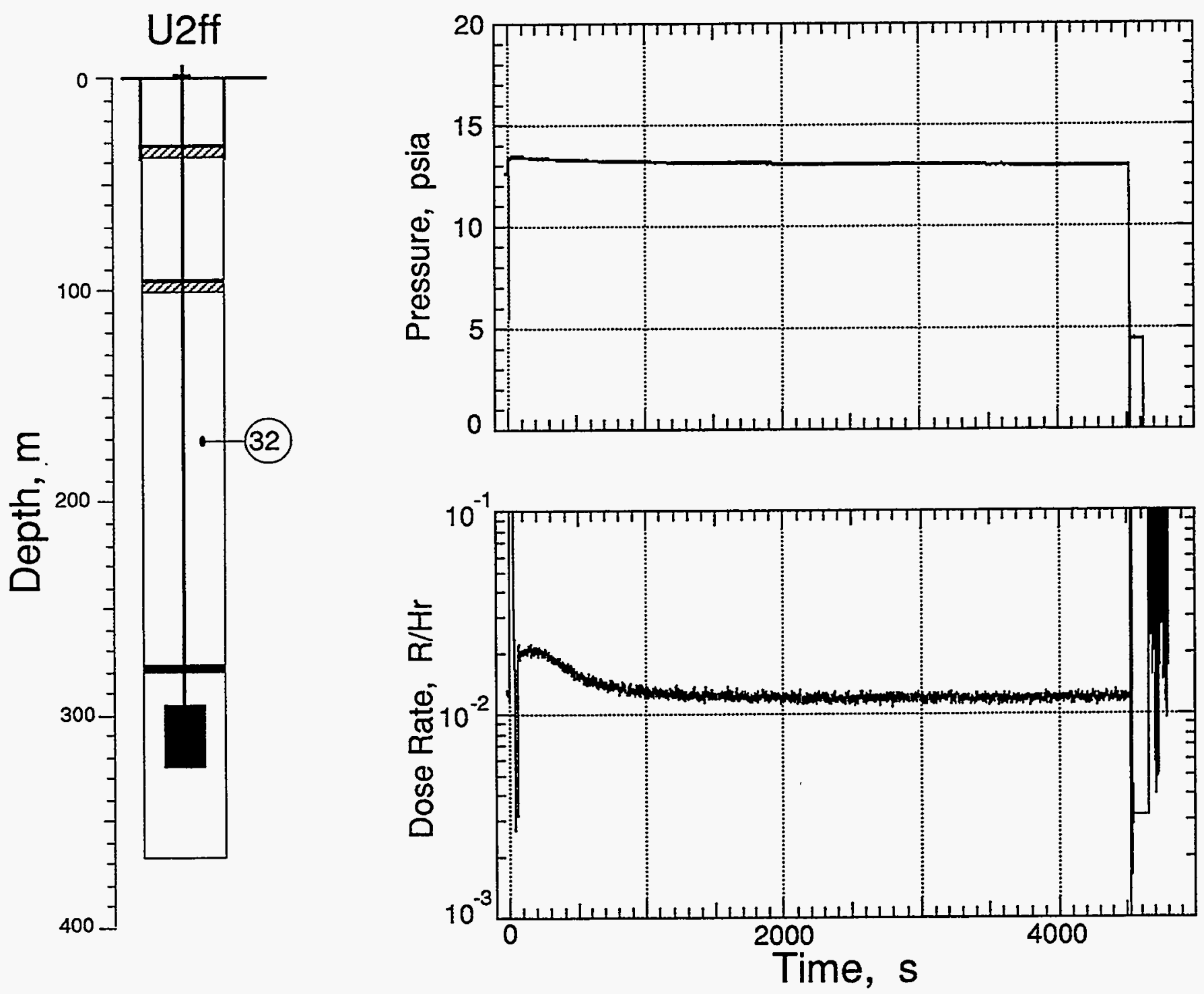

Figure 3.2 Pressure and radiation measured in the coarse stemming at a depth of $170 \mathrm{~m}$ (station 32). 

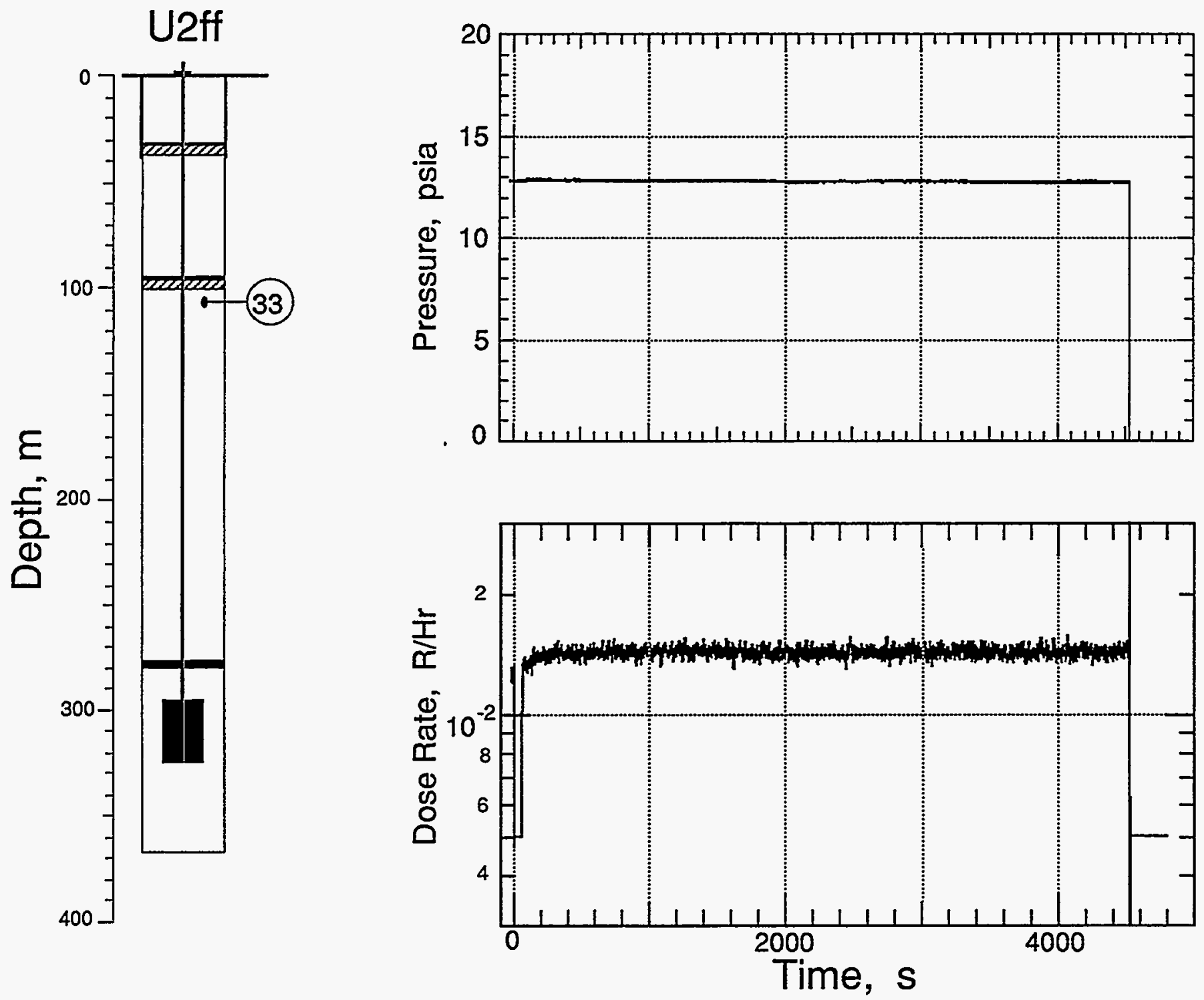

Figure 3.3 Pressure and radiation measured in the coarse stemming beneath the deepest TPE plug (station 33 at a depth of $107 \mathrm{~m}$ ). 

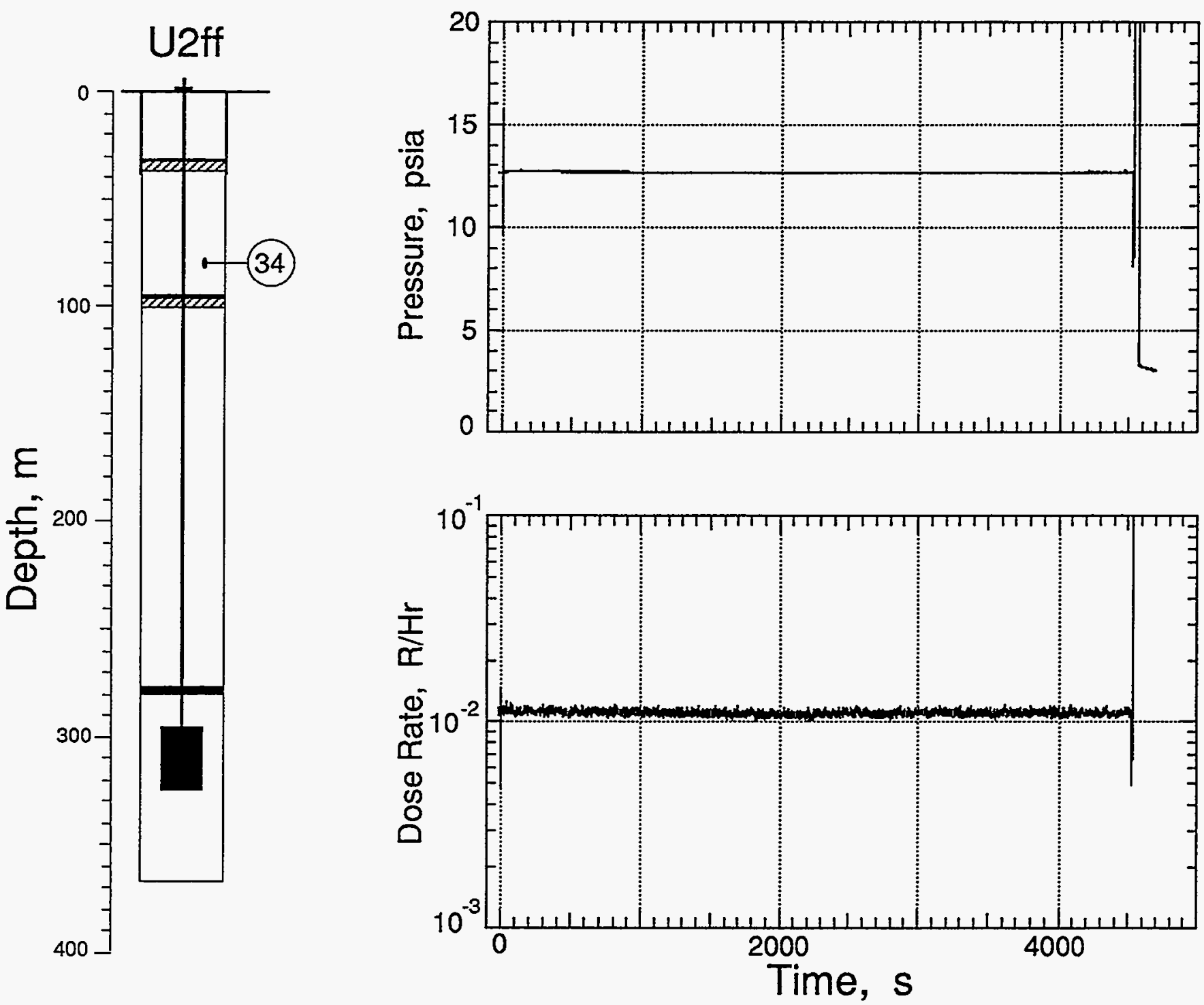

Figure 3.4 Pressure and radiation measured in the coarse stemming at a depth of $79 \mathrm{~m}$ (station 34). 

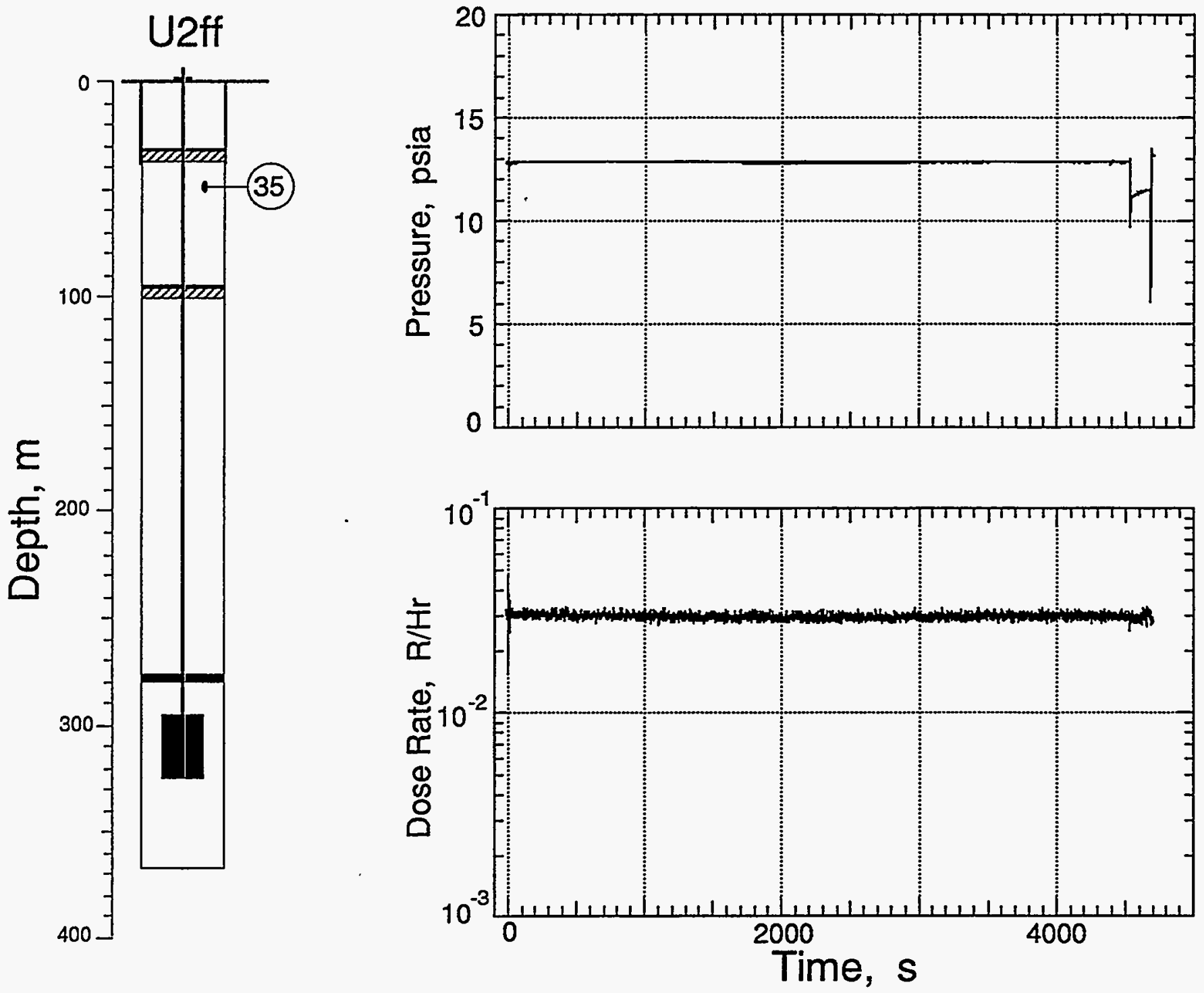

Figure 3.5 Pressure and radiation measured in the coarse stemming at a depth of $49 \mathrm{~m}$ (station 35). 

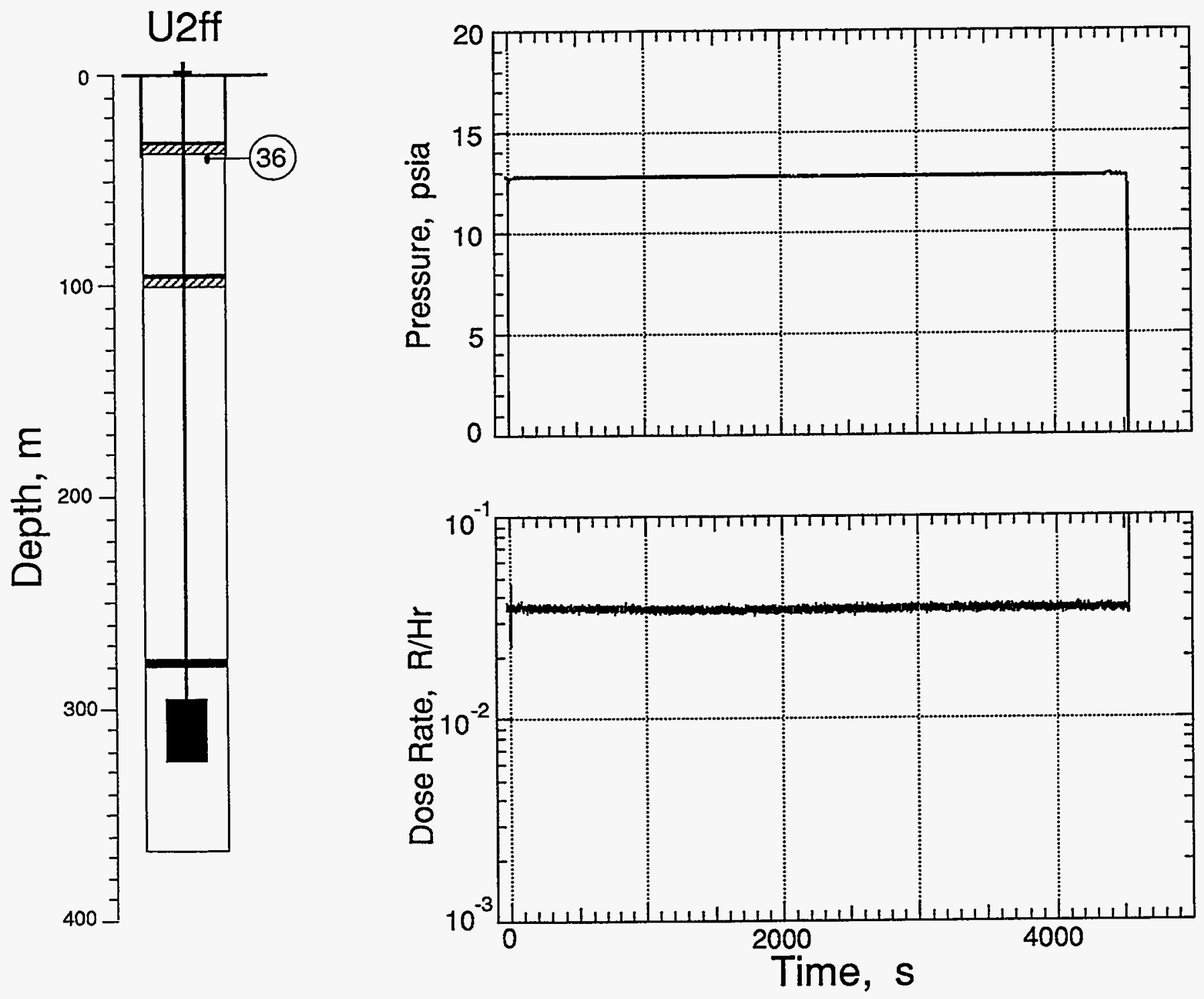

Figure 3.6 Pressure and radiation measured in the coarse stemming beneath the top TPE plug (station 36 at a depth of $39 \mathrm{~m}$ ). 


\subsection{Motion}

Explosion-induced motion histories obtained from the LABAN emplacement hole are shown in figures 3.7-3.11. Characteristics of the motion and of the motion transducers are given in tables $3.1-3.3$.

The agreement between the acceleration and velocity transducers is quite good in spite of the high noise level in the velocity records, particularly so for stations 21 and 62 . The early arrivals most clearly seen in the acceleration records of stations 21,22 and 62 is attributed to a shock traveling in the steel of the emplacement pipe and the strong-backs of the pipe support. There is no measurable displacement due to this motion.

The difference between the displacement histories of stations 22 and 61 (shown in figure 3.12) is an estimate the early time dynamic separation between the surface casing and the top TPE plug. However, the large noise level in the records does not allow a definitive conclusion as to the separation to be made from these data.

The displacement transducer history of station 3 (figure 3.13) suggests that the plug separated by as much as $40 \mathrm{~cm}$ from the surface casing at early times. A comparison of the data of stations 1 and 3 suggest that the stemming column above the top plug was compressed by about $8 \mathrm{~cm}$ while the data of station 2 suggest that the emplacement pipe was lifted a little more than $1 \mathrm{~m}$ above its original position. Close agreement between the displacement histories derived from the accelerometer and velocity gauges at both stations 22 and 62 (figures 3.8 and 3.9) tend to invalidate of the displacement data from stations 1, 2, and 3. 


\section{Table 3.1 Summary of Motion}

\begin{tabular}{|c|c|c|c|c|c|c|}
\hline Gauge & $\begin{array}{c}\text { Slant Range } \\
(\mathrm{m})\end{array}$ & $\begin{array}{l}\text { Arrival Time } \\
\text { (ms) }\end{array}$ & $\begin{array}{l}\text { Acceleration } \\
\text { Peak (g) }\end{array}$ & $\begin{array}{l}\text { Velocity Peak } \\
(\mathrm{m} / \mathrm{s})\end{array}$ & $\begin{array}{l}\text { Displacement } \\
\text { Peak (cm) }\end{array}$ & $\begin{array}{l}\text { Displacement } \\
\text { Residual (cm) }\end{array}$ \\
\hline $21 a v$ & 226.8 & $57^{(a)}, 114$ & 1.85 & $0.28,0.41$ & 7.9 & -11 \\
\hline $21 u v$ & - & - & - & $0.28,0.43$ & 8.2 & $-5(b)$ \\
\hline $22 a v$ & 290.5 & $72(a), 156$ & 0.79 & $0.25,0.39$ & 6.6 & -5 \\
\hline $22 u v$ & - & - & - & $0.26,0.39$ & 6.5 & -6.5 \\
\hline $61 a v$ & 325.4 & 190 & $1.5,8.4^{(c)}$ & $0.49,-1.09$ & 5.7 & -10 \\
\hline 61uv & - & - & - & $0.50,-1.18$ & 5.8 & $-5^{(b)}$ \\
\hline $62 a v$ & 326.0 & $83(a), 173$ & 0.9 & $0.37,-0.82$ & 6.4 & -10 \\
\hline $62 u v$ & - & - & - & $0.37^{(b)},-0.8^{(b)}$ & 5.5 & -7 \\
\hline $71 a v$ & 365 (d) & 225 & 1.43 & 0.55 & 4.5 & -8 \\
\hline $71 u v$ & - & - & - & 0.54 & 4.3 & -8 \\
\hline $1 d v$ & $324.5^{(e)}$ & - & - & - & - & $50(f)$ \\
\hline $2 d v$ & $324.5^{(e)}$ & - & - & - & - & $160^{(f)}$ \\
\hline $3 d v$ & $292.2^{(e)}$ & - & - & - & - & $42^{(f)}$ \\
\hline
\end{tabular}

\footnotetext{
(a) Pipe-induced motion.

(b) Very high noise level - value uncertain.

(c) Slap-down peak.

(d) Gage in recording trailer, range approximate.

(e) Position of anchor.

(f) Gage output questionable.
} 


\section{Table 3.2 Accelerometer Characteristics}

\begin{tabular}{|c|c|c|c|}
\hline Gauge & $\begin{array}{l}\text { Natural Frequency } \\
.(\mathrm{Hz})\end{array}$ & Damping Ratio & $\begin{array}{l}\text { System Range } \\
\text { (g's) }\end{array}$ \\
\hline $21 \mathrm{av}$ & 258 & 0.65 & 8 \\
\hline 22av & 272 & 0.75 & 8 \\
\hline $61 \mathrm{av}$ & 430 & 0.65 & 20 \\
\hline $62 a v$ & (a) & (a) & 8 \\
\hline $71 a v$ & 240 & 0.75 & 5 \\
\hline
\end{tabular}

(a) Unknown.

\section{Table 3.3 Velocimeter Characteristics}

\begin{tabular}{|c|c|c|c|c|c|}
\hline Gauge & $\begin{array}{l}\text { Natural } \\
\text { Frequency } \\
(\mathrm{Hz})\end{array}$ & $\begin{array}{l}\text { Time to } 0.5 \\
\text { Amplitude } \\
\text { (s) }\end{array}$ & $\begin{array}{c}\text { Calibration } \\
\text { Temperature } \\
\text { (年) }\end{array}$ & $\begin{array}{c}\text { Operate } \\
\text { Temperature } \\
\text { (०) }\end{array}$ & $\begin{array}{c}\text { System } \\
\text { Range } \\
(\mathrm{m} / \mathrm{s})\end{array}$ \\
\hline 21uv & 3.514 & 9.38 & 23.75 & 35.60 & 6 \\
\hline $22 u v$ & 3.430 & 10.04 & 23.96 & 53.51 & 8 \\
\hline 61uv & 3.120 & 11.01 & 25.54 & 25.67 & 8 \\
\hline $62 u v$ & (a) & 9.79 & 23.33 & 22.40 & 8 \\
\hline 71uv & 3.5 & 8.21 & 25.04 & 20.56 & 2 \\
\hline
\end{tabular}

(a) Unknown. 

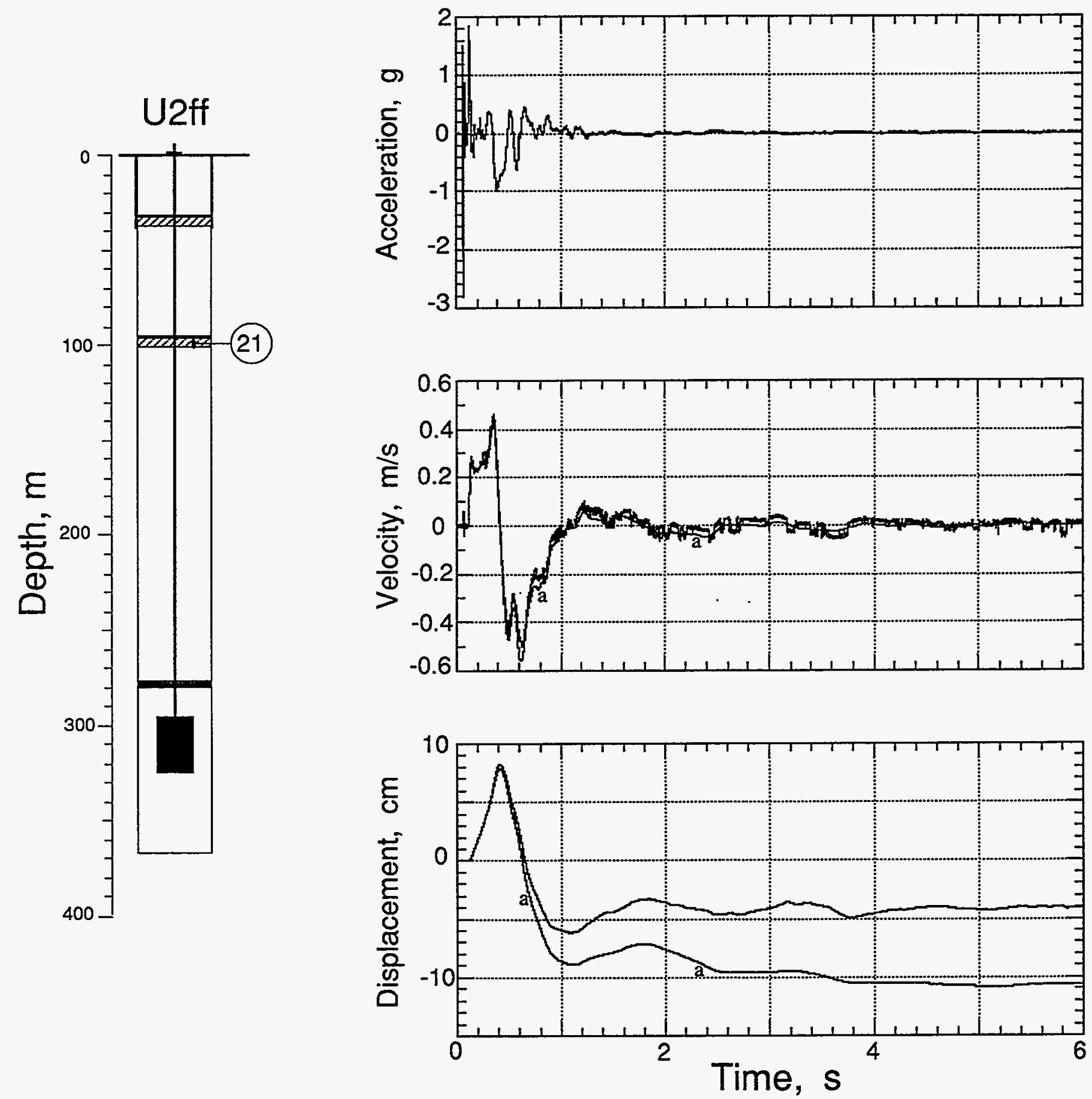

Figure 3.7 Explosion-induced vertical motion of the deepest TPE plug (station 21 at a depth of $99 \mathrm{~m})$. Traces annotated with "a" are derived from the accelerometer. 

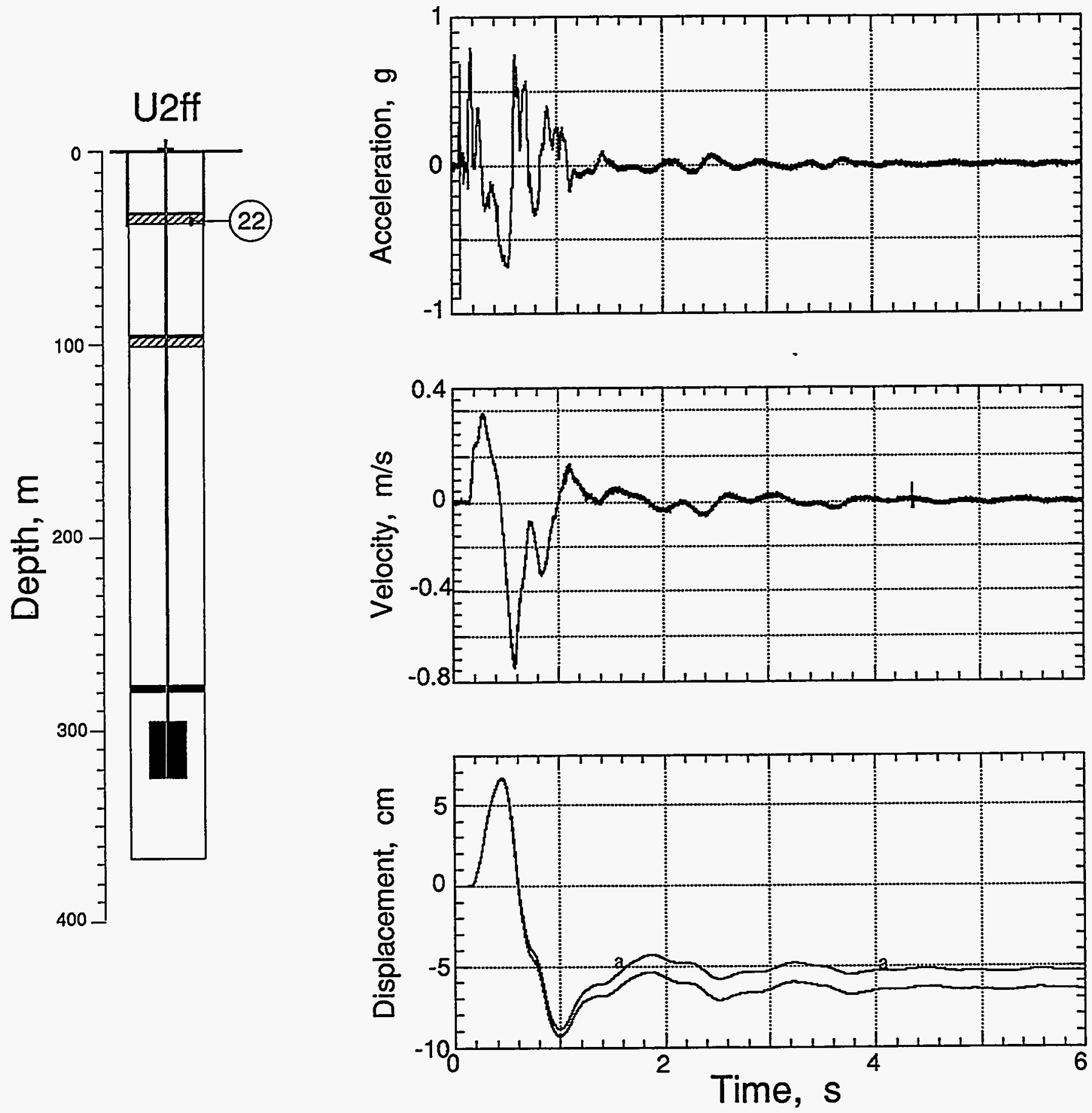

Figure 3.8 Explosion-induced vertical motion of the top TPE plug (station 22 at a depth of 35 $\mathrm{m})$. Traces annotated with " $a$ " are derived from the accelerometer. 

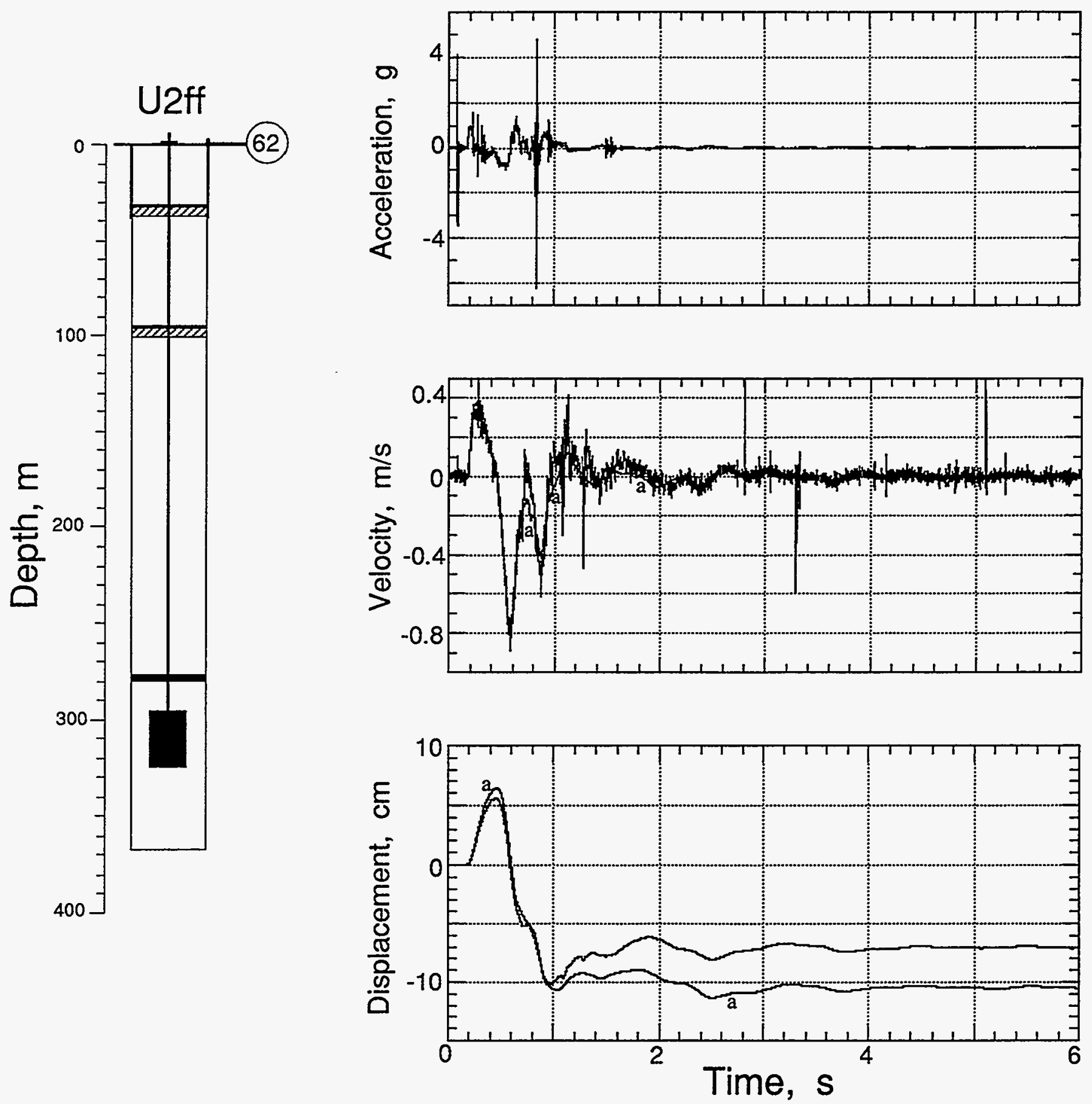

Figure 3.9 Explosion-induced vertical motion of the top of the surface casing (station 62 at a depth of $99 \mathrm{~m}$ ). Traces annotated with "a" are derived from the accelerometer. 

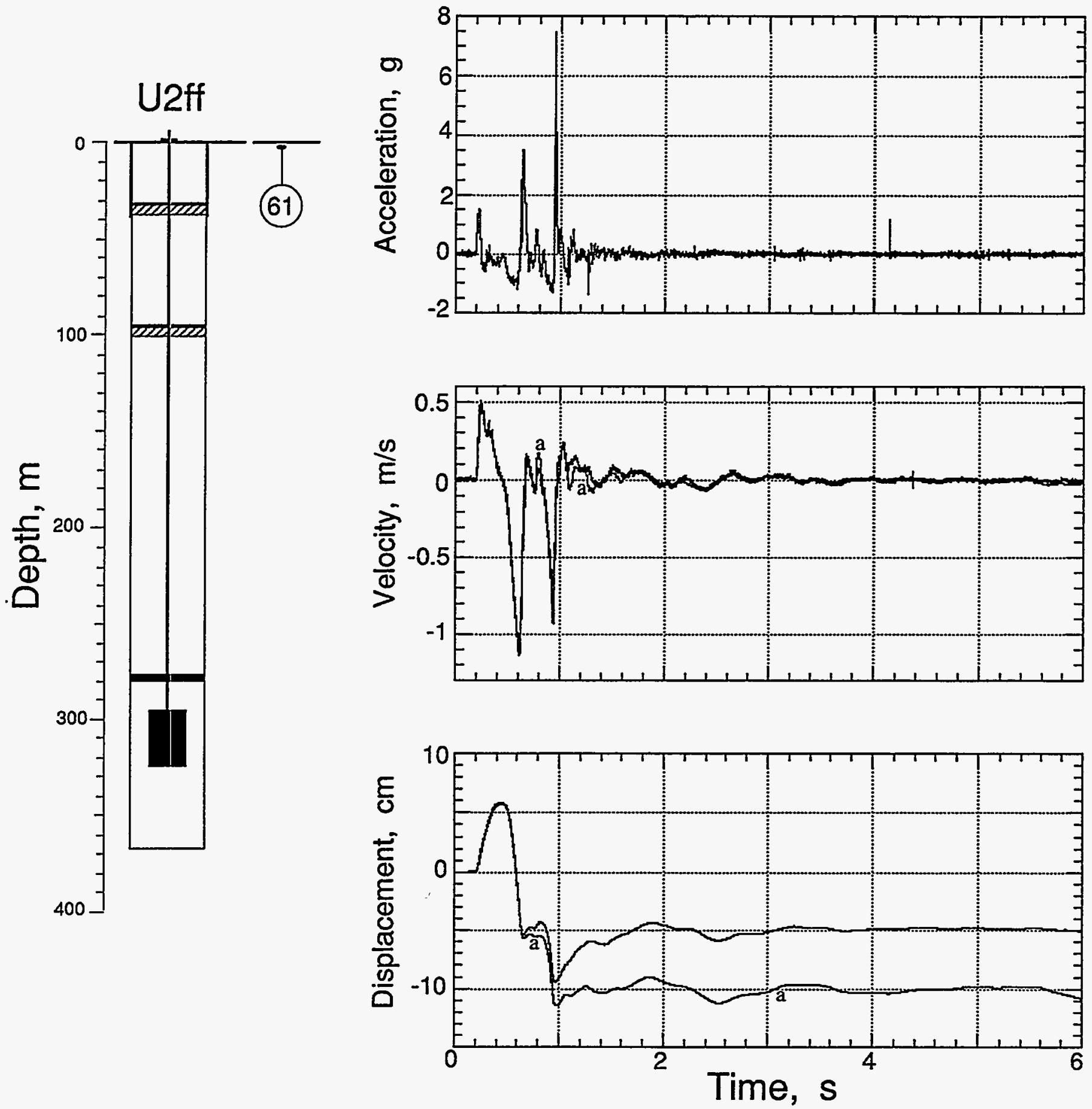

Figure 3.10

Explosion-induced vertical motion of the ground surface (station 61 at a depth of $0.9 \mathrm{~m}$ and horizontal range of $15.24 \mathrm{~m}$ ). Traces annotated with "a" are derived from the accelerometer. 


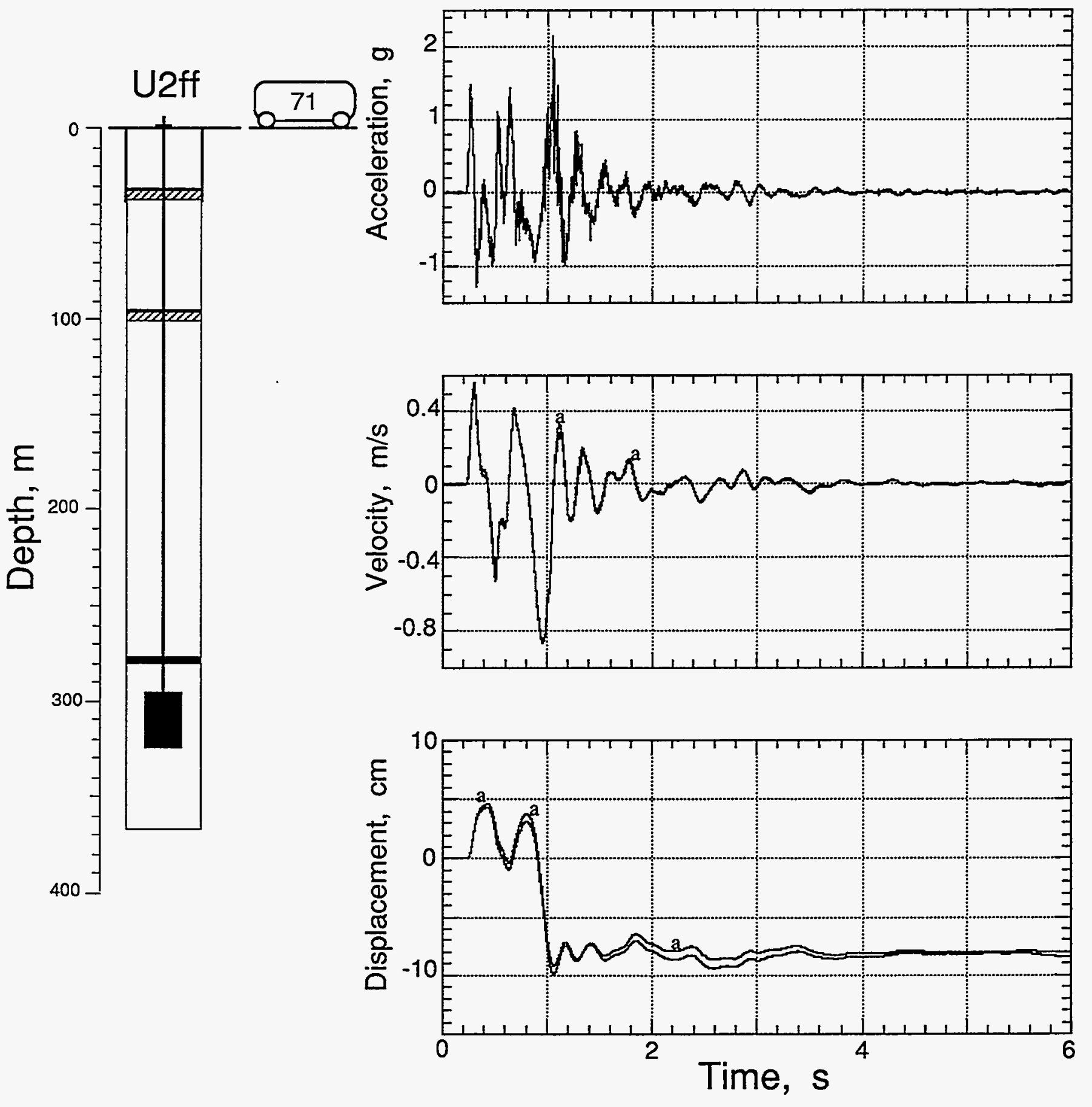

Figure 3.11 Explosion-induced vertical motion of the recording trailer (station 71). Traces annotated with "a" are derived from the accelerometer. 

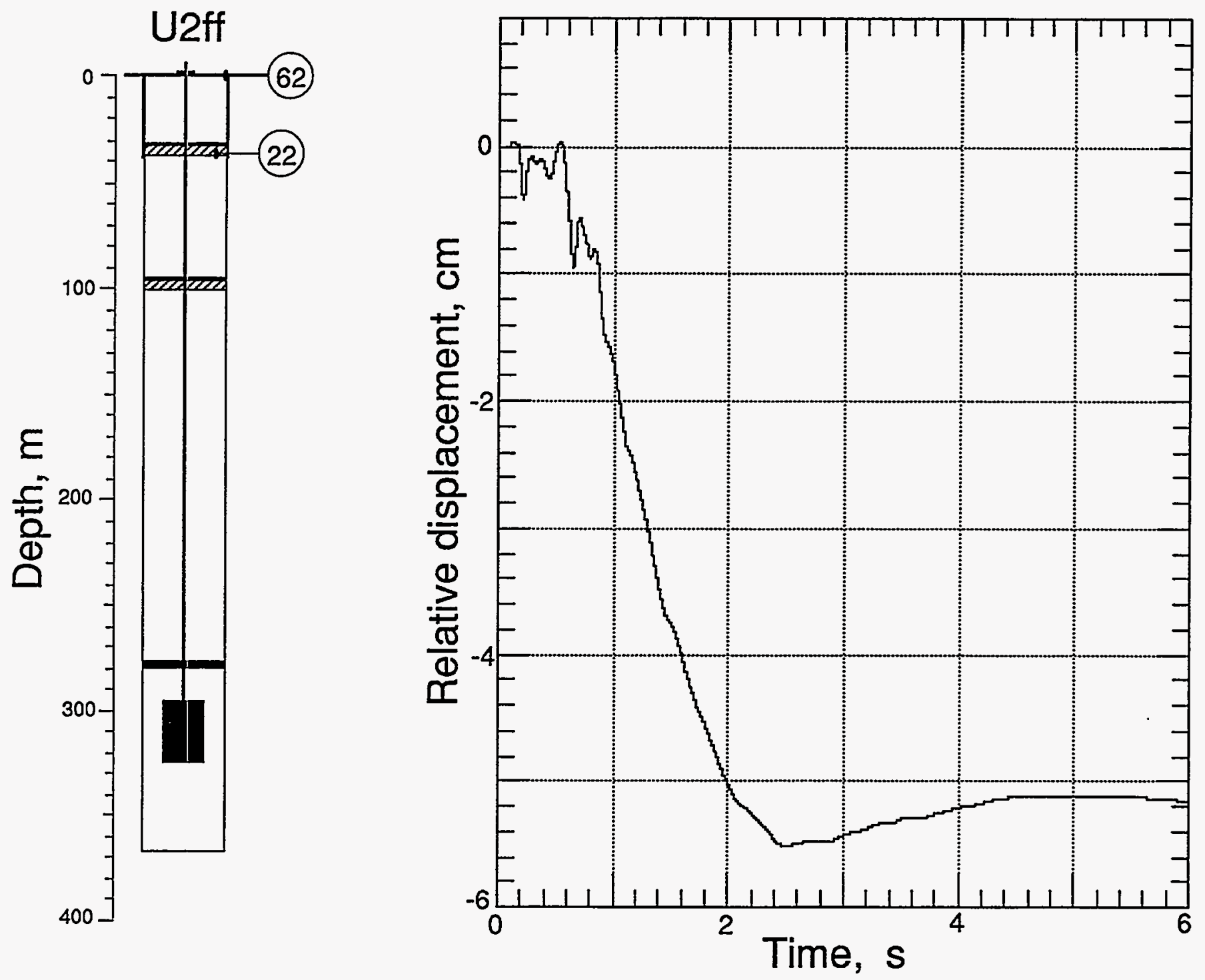

Figure 3.12 Relative displacement between surface casing and top TPE plug (displacement of station 62 less that of station 22). 


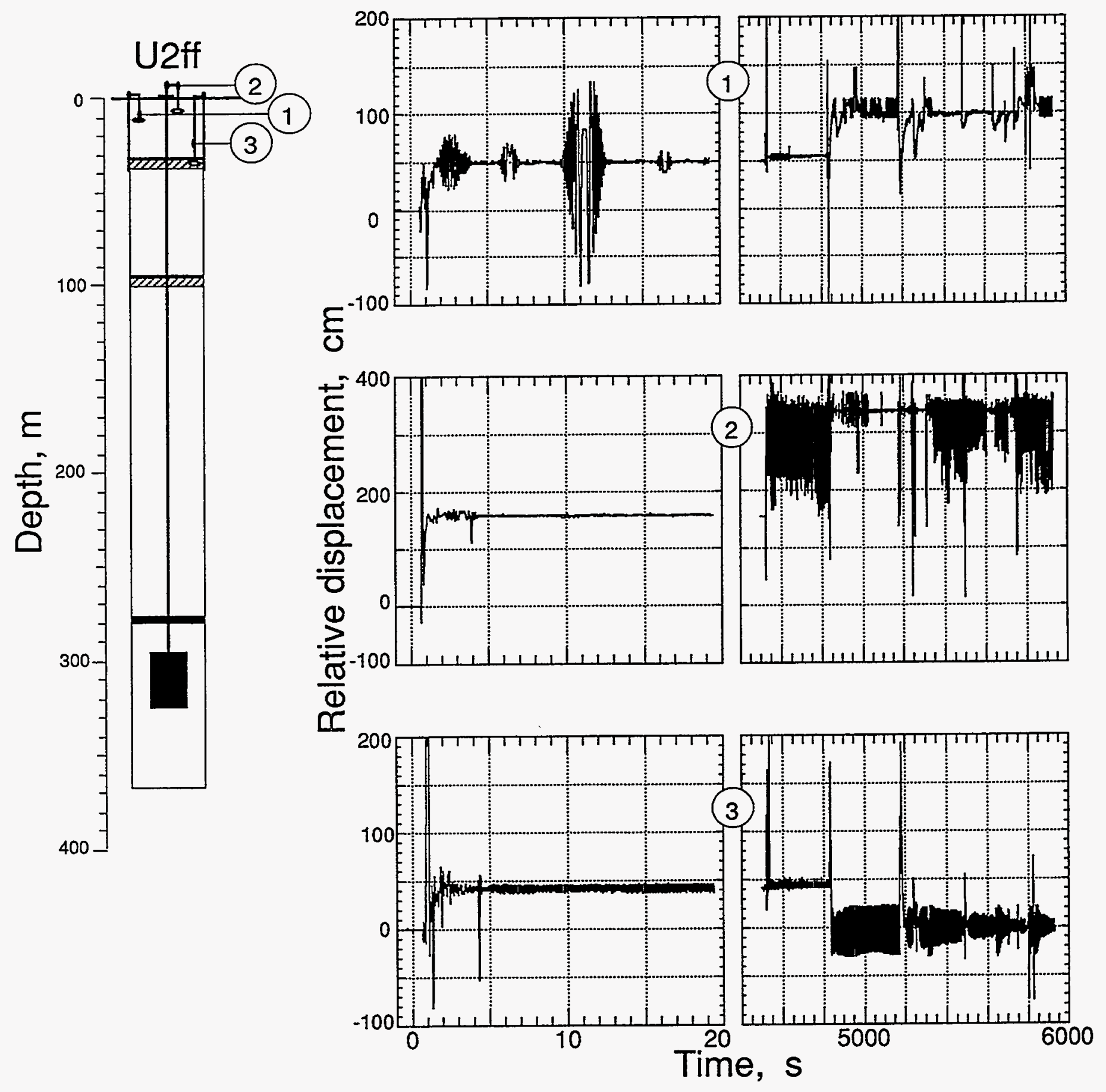

Figure 3.13 Celesco displacement transducer output. Stations 1 and 2 were anchored in the coarse stemming and station 3 was anchored in the top TPE plug. All data required digital low-pass filtering at $5 \mathrm{~Hz}$. These data are suspect. 


\subsection{Collapse phenomena}

Approximately 1.25 hours after detonation the first collapse signal arrived at station 21. Figure 3.14 shows the progression of the collapse front as determined from the CLIPER (station 92) along with the pressure wave forms showing the loss of pressure signal as the collapse front passes. Also included is the displacement history of station 21 (see figure 3.15). None of these traces have been scaled to the vertical dimension; they are for timing only.

The motion measured during the major collapse events seen at each motion station are shown in figures 3.15 - 3.18. The accelerometer signal from station 21 was lost about $90 \mathrm{~s}$ after the motion shown in figure 3.15 and the velocimeter at around $70 \mathrm{~s}$. No clear motion at any station was recorded at these times and it is assumed that the loss was due to cable breakage at a shallower depth. Station 61 in the ground surface (figure 3.18 ) was unable to detect more than a slight indication of the collapse and the resulting signals are shown for completeness only. The recording trailer (station 71) detected nothing during the collapse period and is thus not represented.

Station 22, at the bottom of the surface casing (figure 3.16 ), and station 62 , on the surface casing (figure 3.17) remained viable until recording was terminated. About 5 minutes after the subsurface collapse represented in figure 3.15 there was a major surface fall of nearly $30 \mathrm{~m}$ followed by a series of lesser drops lasting for nearly 20 minutes. Only the major fall is represented in figures 3.16 and 3.17. Comparison of the displacements registered in figures 3.16 and 3.17 indicates that the plug fell about $5 \mathrm{~m}$ farther that the surface casing during the major excursion.

An estimate to the total vertical excursion of station 22 is obtained by dividing the time history into short periods including the prominent motions and processing these segments individually. Eight of these subsections of the acceleration history are shown in the bottom plot of figure 3.19. The dashed lines are the supposed continuation of the history between the sections. A total fall of nearly $50 \mathrm{~m}$ is indicated. 
The station 22 accelerometer record rather than the data of station 62 was used for this exercise for at least three reasons. First, the data are more free of noise introduced both electronically and from signals transmitted through the steel of the casing. Second, it was felt that the plug, if it was detached from the casing, would represent a more accurate description of the ground. And third, since there was a very large displacement, it was expected that the station would not remain in a perfect vertical orientation and the accelerometers are much less sensitive to rotation than the over-damped paddle velocity transducers used on this experiment.

In particular, if a paddle gauge is subjected to a long period of nearly constant acceleration or rotation, the output will require correction to obtain a correct representation of the motion. This is discussed in section 4. Given a long enough history of a paddle gauge under rotation, an estimate of the final station rotation can be estimated as is done in the top plot of figure 3.19. The velocimeter of station 62 was used since it was mounted to the top of the surface casing and, for that reason, was expected to undergo less rotation than station 22 . The pendulum stop-to-stop swing is 13 degrees and represents a velocity difference of $61.6 \mathrm{~m} / \mathrm{s}$ for the gauge in question. Each of the collapses shown is represented by a velocity excursion followed by a period of exponential decay having a $\frac{1}{e}$ time of $12.4 \mathrm{~s}$. Noting that several of the episodes did not last long enough for the gauge to come to equilibrium at each episode, the final rotation plotted is a lower limit. 


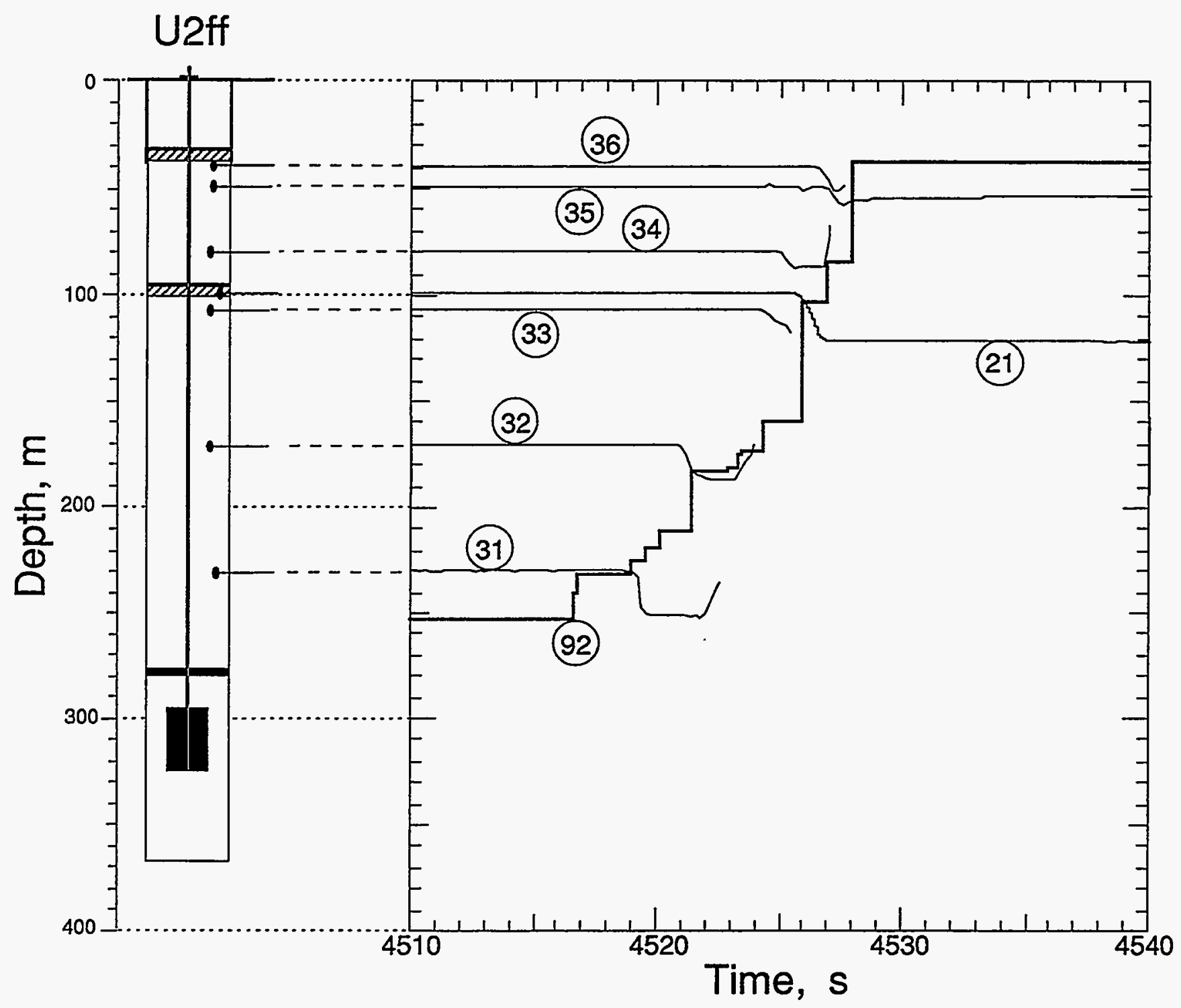

Figure 3.14 Progression of collapse in stemming column as indicated by CLIPER data (station 92). Also shown are all the pressure wave forms and the station 21 displacement wave form (none to vertical scale). 

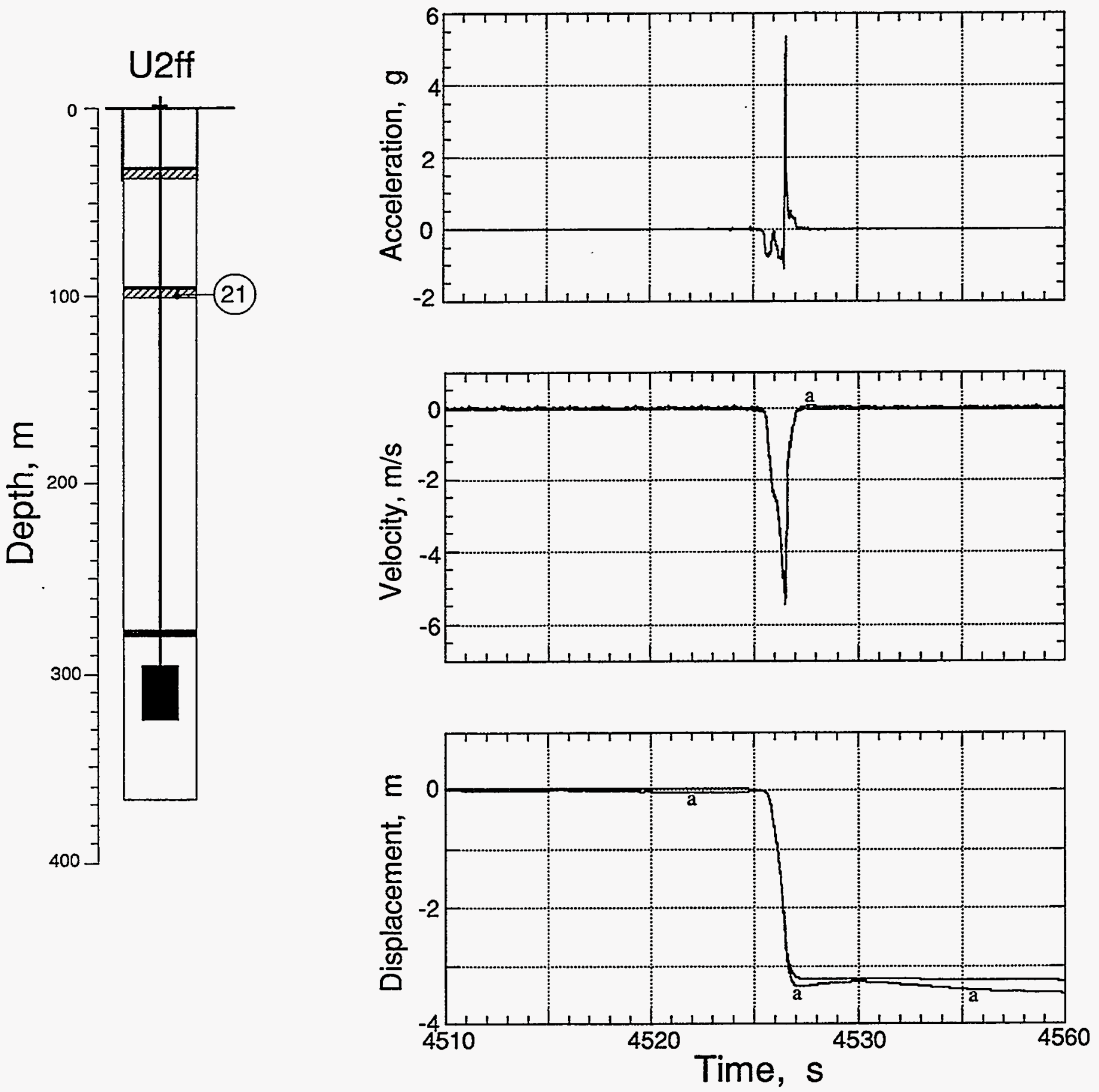

Figure 3.15 Collapse-induced vertical motion of the deepest TPE plug (station 21 at a depth of $99 \mathrm{~m}$ ). Traces annotated with "a" are derived from the accelerometer. 

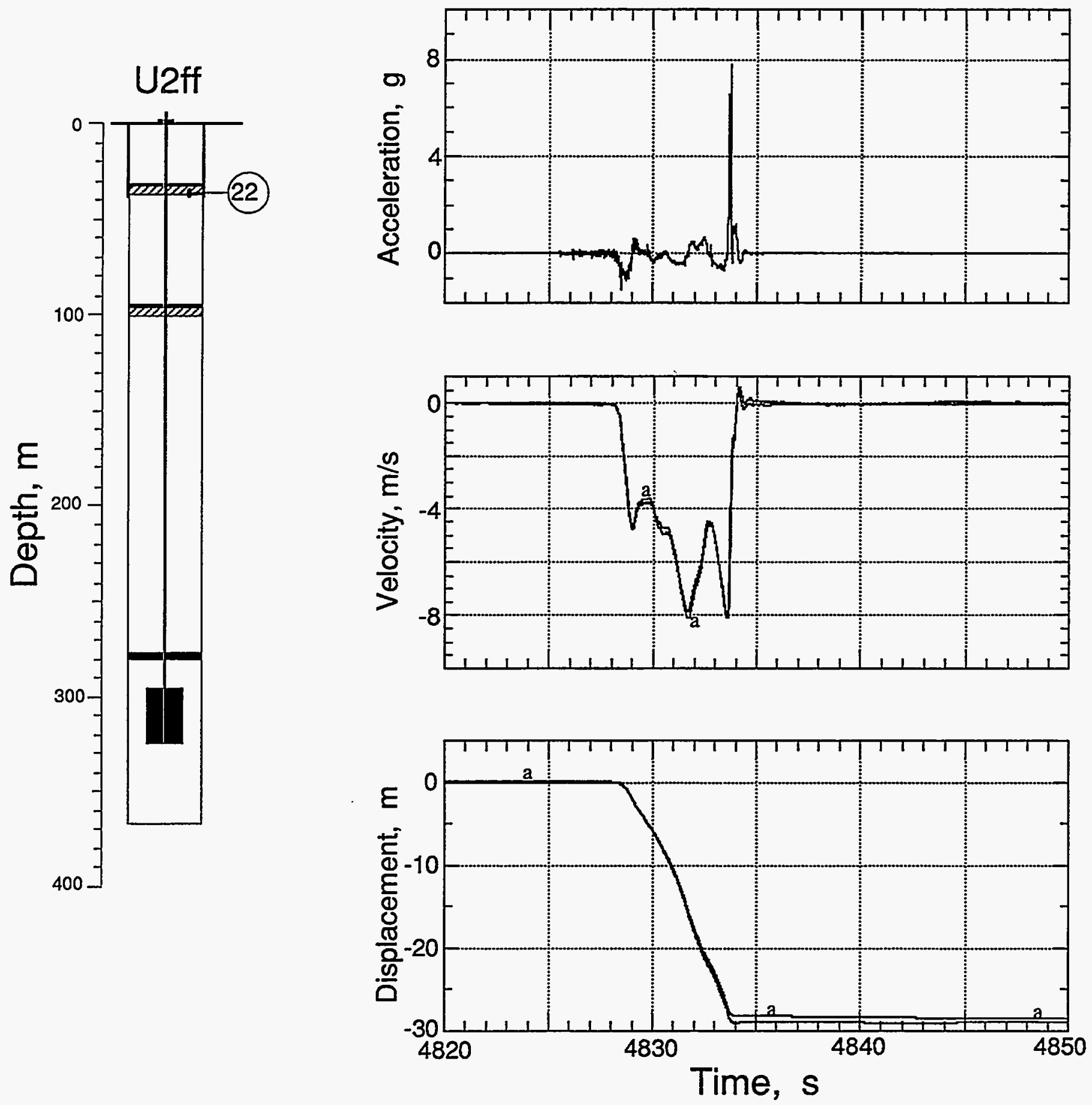

Figure 3.16 Collapse-induced vertical motion of the top TPE plug (station 22 at a depth of 35 $\mathrm{m})$. Traces annotated with "a" are derived from the accelerometer. 

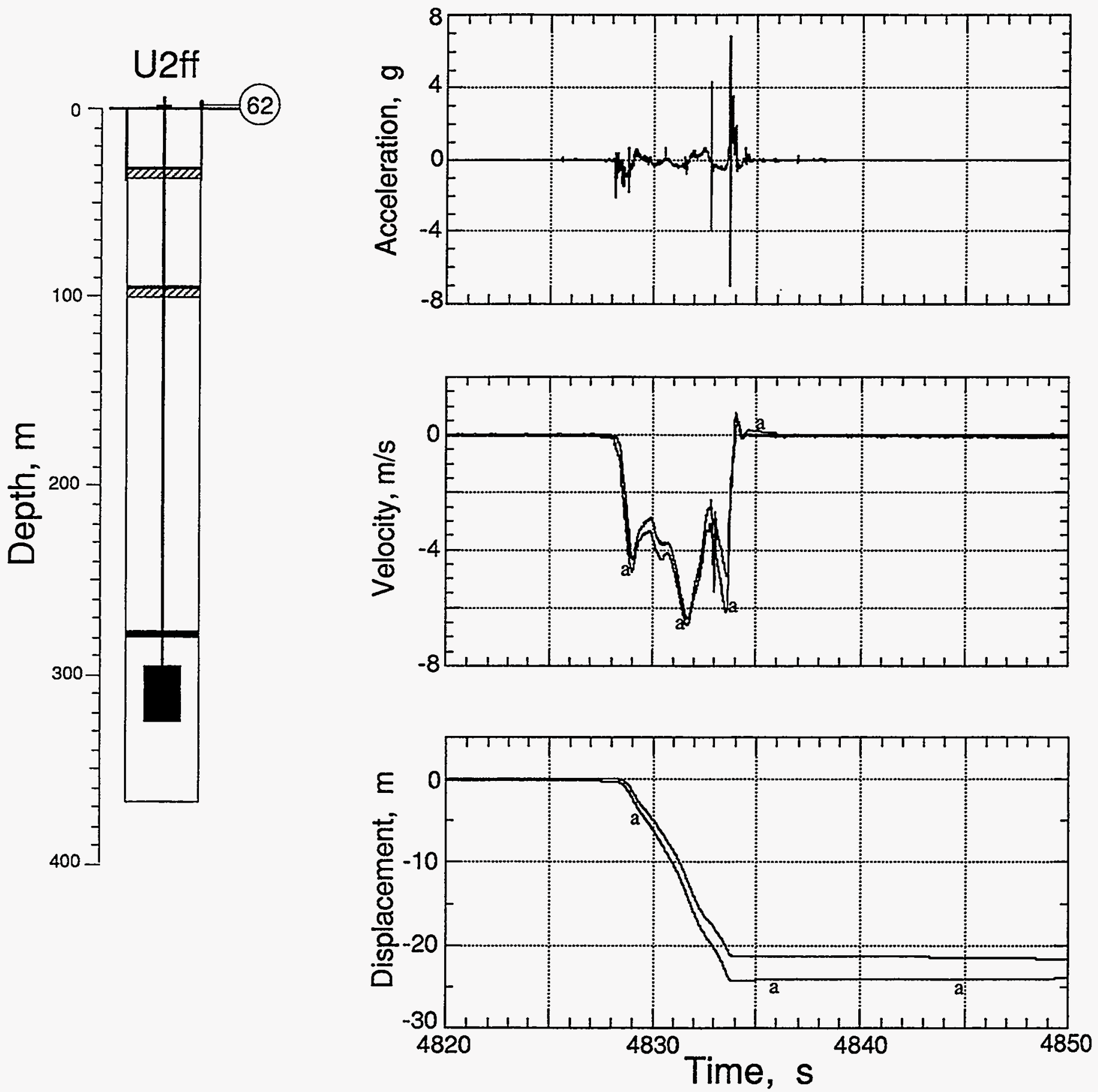

Figure 3.17 Collapse-induced vertical motion of the top of the surface casing (station 62 at a depth of $99 \mathrm{~m}$ ). Traces annotated with "a" are derived from the accelerometer. 


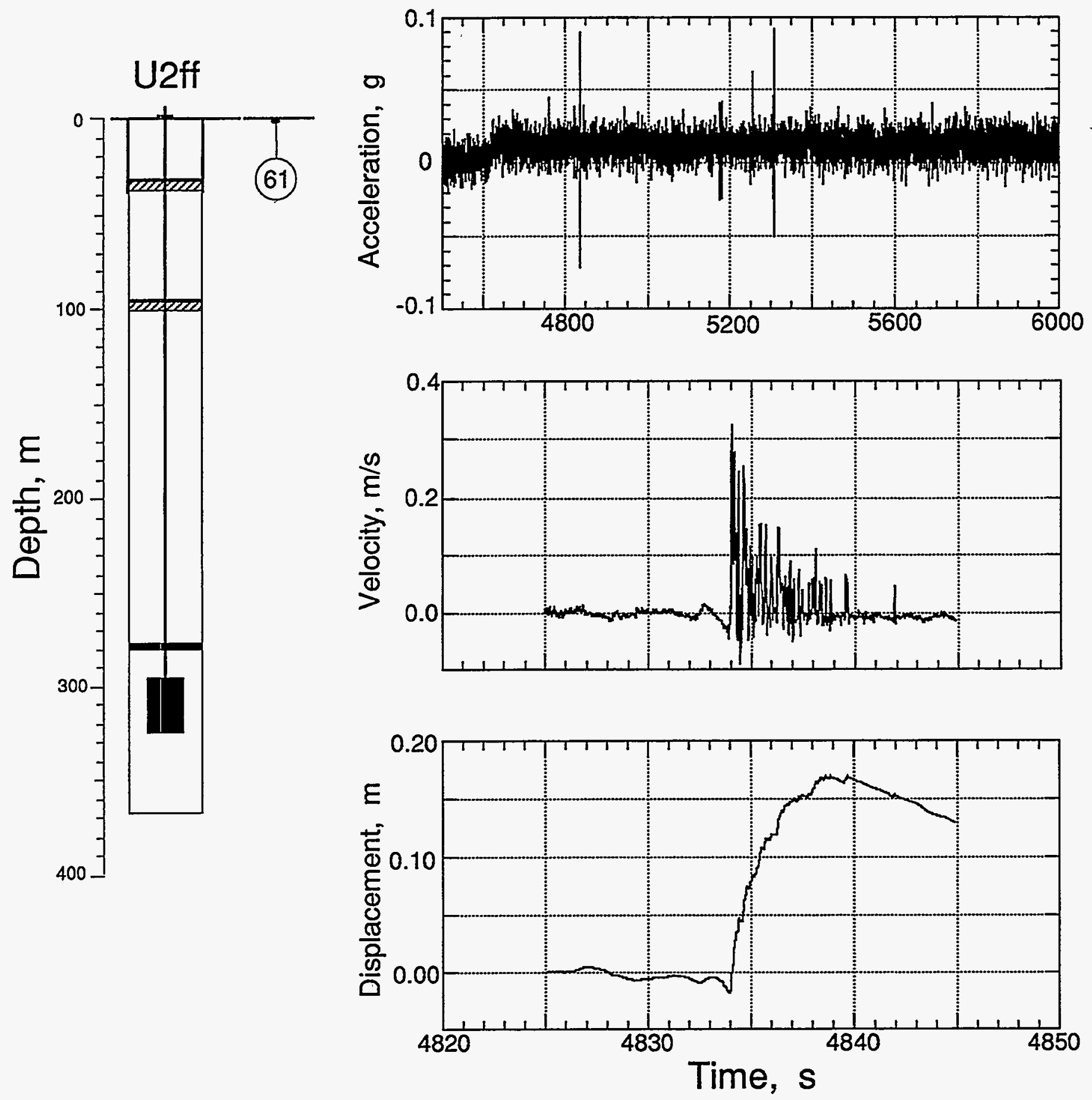

Figure 3.18 Collapse-induced vertical motion of the ground surface (station 61 at a depth of $0.9 \mathrm{~m}$ and horizontal range of $15.24 \mathrm{~m}$ ). 

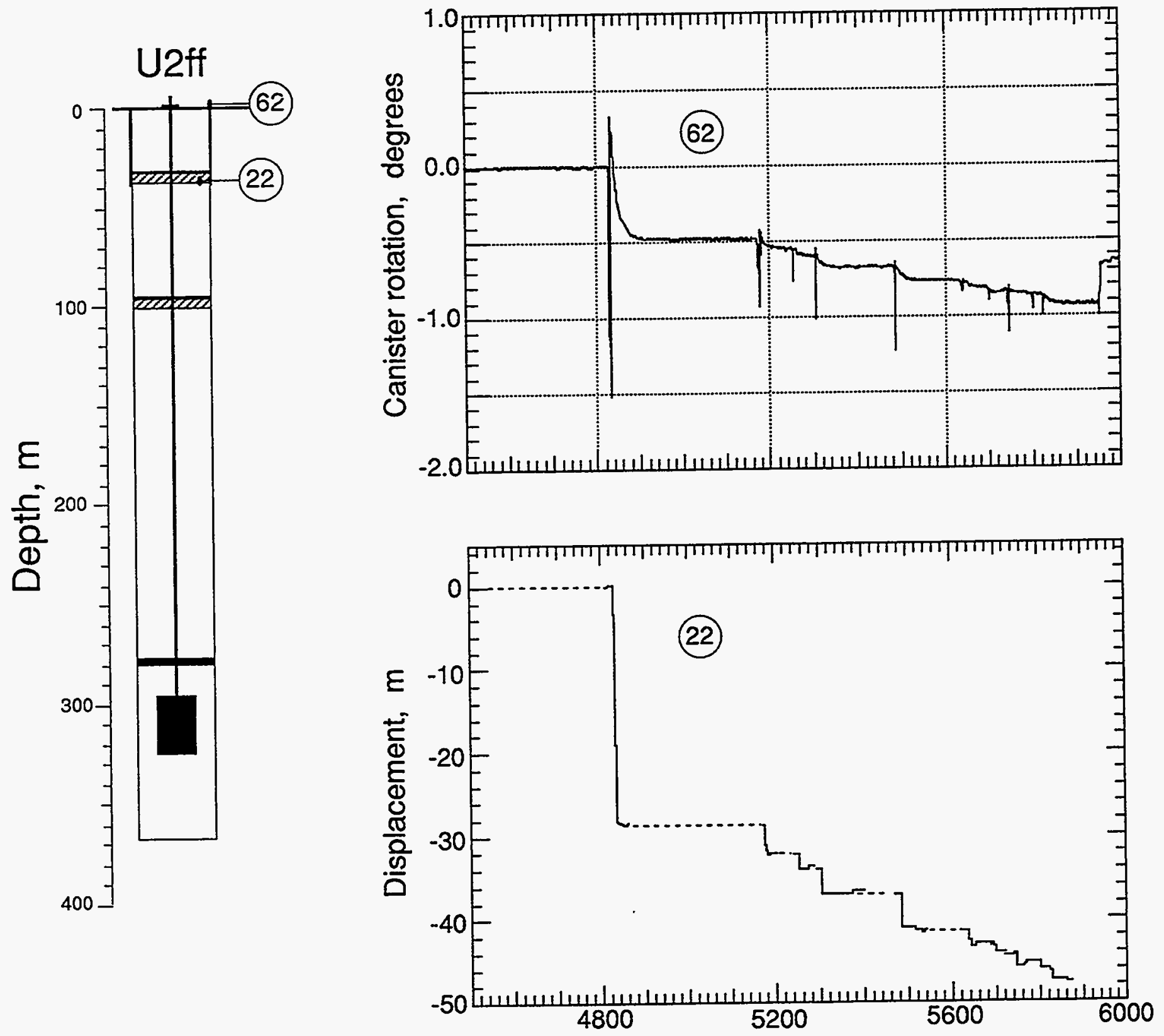

Figure 3.19 The upper plot shows a 25 minute history of the paddle velocity gauge at station 62 (on the surface casing) calibrated for paddle rotation. Only the periods of constant rotation are to be used; the transitions are due to gauge response. The lower plot is composed of individual sections of the accelerometer record from station 22 (in the top TPE plug). The dashed lines are hypothetical continuations of the data between sections. 


\section{Phase Correction of an Over-damped Pendulum Velocity Gauge}

The over-damped pendulum gauge, analyzed by Perret ${ }^{(5)}$, has been for many years the transducer of choice for measuring velocity signals from high yield explosions. This device gives a good representation of the velocity so long as the motion is quasi-oscillatory within the frequency limits of the device. However, if the applied input includes a long period of acceleration (as in free-fall) or rotation, the gauge output gives a distorted picture of the true velocity.

Intuitively, this may be understood by a simple "gedanken" experiment. Consider an over-damped paddle gauge oriented to measure vertical motion. The paddle of this device is suspended in a viscous oil at the null position by a spring under static gravity. Now allow the gauge to be dropped in free-fall for an extended period followed by a sudden halt to the motion. The pendulum will be pulled up (relative to the gauge housing) by the spring during the fall and when the motion ceases (abruptly) will have to "recover" from the offset by moving through a viscous oil. Since the gauge is heavily over-damped (the damping constant is usually greater that 100 ), the time constant of this exponential recovery can be long (greater than $10 \mathrm{~s})$.

More precisely, the equation of motion of a damped pendulum is:

$$
\ddot{x}(t)+2 \omega h \dot{x}(t)+\omega^{2} x(t)=A(t)
$$

Here

$$
\begin{aligned}
x(t) & \equiv \text { position of transducer coil pickup } \\
\omega & \equiv \text { undamped natural frequency of pendulum } \\
h & \equiv \text { damping ratio } \\
\text { and } \quad A(t) & \equiv \text { externally applied acceleration. }
\end{aligned}
$$

Let us now define $2 h \omega \equiv \frac{1}{T_{s}}$ and $\frac{\omega}{2 h} \equiv \frac{1}{T_{L}}$, the short- and long-term time constants of the system, respectively, and the "calibrated" system output $2 h \omega x(t) \equiv X(t)$, equation (1) becomes.

$$
T_{S} \ddot{X}(t)+\dot{X}(t)+\frac{1}{T_{L}} X(t)=A(t)
$$


Since $T_{s}$ is usually quite small $\left(\leq 10^{-3}\right)$ we have, upon neglecting the left hand term in equation (2) and integrating;

$$
V(t)=U(t)+\frac{1}{T_{L}} \int_{-\infty}^{t} U(\tau) d \tau
$$

Note that $V(t)$ is the integral of all of the applied accelerations, including gauge rotations while $U(t)=X(t)$, the velocity transducer output.

Figure 4.1 is shown as a demonstration of the gauge response correction operations that were applied to the collapse record obtained from station 21 , in the deepest TPE plug. The top-most plot shows the raw data, as digitized, while the middle plot is the time history, $V(t)$, obtained from the application of equation (3) to history of the top plot, $U(t)$ using the time constant $T_{L}=11.11 \mathrm{~s}$. The integral of a constant acceleration, assumed to be the result of rotation of the station, is observed in the middle plot and subtracted from the velocity record to produce the bottom plot which is taken to be the best estimate of the vertical velocity history. Since the rotation history is unknown, this is only an estimate. However, from observation of the middle plot, it seems likely that the rotation occurred only during the velocity excursion. Thus, a single baseline shift, starting during the excursion, making the velocity zero at late times, is postulated to be adequate.

The amount of the (constant) acceleration is determined from the slope of the $V(t)$ history at late time to be $8 \times 10^{-4} \mathrm{~g}$ 's. (The calibration of this channel was $5.46 \times 10^{-4} \frac{\mathrm{m} / \mathrm{s}}{\text { count }}$ ). 

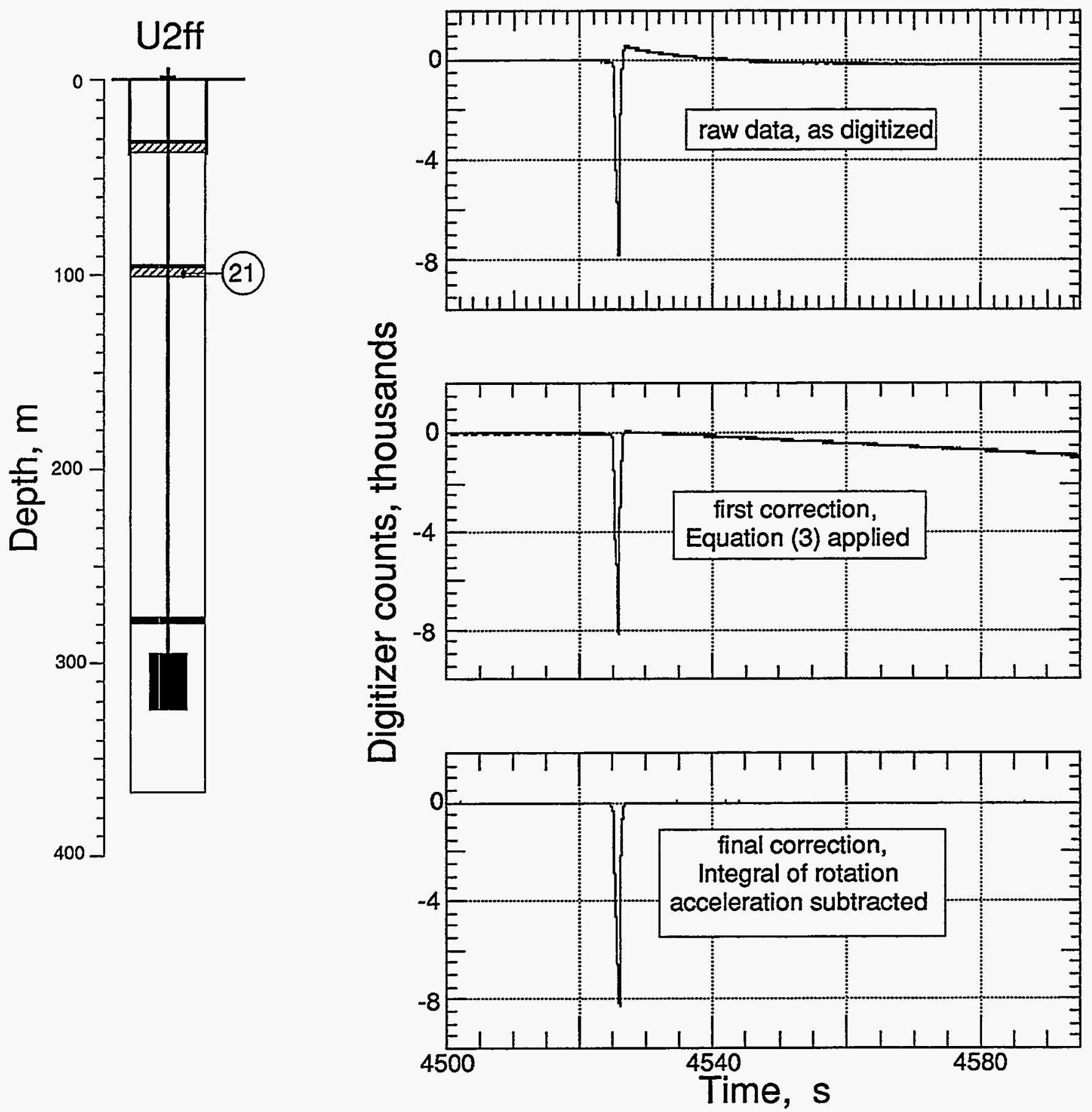

Figure 4.1 Display of the steps necessary to correct the gauge response of an over-damped pendulum velocity gauge. 


\section{References}

1. Stephen R. Clark and Nancy W. Howard, "U2ff Site Characteristics Report," CP 83-16, Lawrence Livermore National Laboratory, Livermore, CA, February 1, 1983.

2. Alfred E. Burer, "Emplacement and Containment Report for LABAN U2ff," Holmes \& Narver, NTS:A2:83-69, August 2, 1983.

3. LLNL contacts for additional information: H. Goldwire and R. A. Heinle (CORRTEX and SLIFER data)

4. Lee E. Davies, "Special Measurements Final Engineering Report LABAN, U2ff", EG\&G, Energy Measurements, Las Vegas, NV, SM:83E-106-38, 31 August 1985.

5. Lee E. Davies, 'Special Measurements, Final, As Built, Physics/Instrumentation Package for LABAN, U2ff (Revision "A")', EG\&G, Energy Measurements, Las Vegas, NV, SM:83E-10639, 31 August 1983.

5. W. E. Perret, "Project Dribble SALMON Event, Free-Field Particle Motion, Part I", Vela Uniform Program, VUF-3112, June 21, 1968 (Sandia Laboratory, Albuquerque, NM). 
Distribution:

LLNL

TID (11)

Test Program Library

Containment Vault

Burkhard, N.

Cooper, $W$.

Denny, $M$.

Goldwire, $H$.

Heinle, R. (5)

Mara, G.

Moran, M. T.

Moss, $W$.

Patton, $\mathrm{H}$,

Pawloski, G.

Rambo, J.

Roth, B.

Valk, T.

Younker, L.

LANL

App, F.

Brunish, W.

Kunkle, $\mathrm{T}$.

Trent, B.

\section{Sandia}

Chabai, A.

Smith, Carl W.
L-053

L-045

L-221

L-221

L-049

L-205

L-221

L-221

L-049

L-777

L-200

L-205

L-221

L-200

L-049

L-154

L-203

F-659

F-659

F-665

F-664

MS-1159

MS-1159
EG\&G/AVO

Brown, $T$.

Gilmore, $\mathrm{L}$.

Hatch, $M$.

Still, G.

Stubbs, T.

A-5

A-1

A-5

A-5

A-5

EG\&G/NVO

Bellow, B.

N 13-20

Davies, $L$.

Moeller, A.

N 13-20

N 13-20

Webb, W.

N $13-20$

DNA

Ristvet, B.

\section{S-Cubed}

Peterson, E.

Eastman Cherrington Environment

1640 Old Pecos Trail, Suite H

Santa Fe, NM 87504

Keller, C. 